\title{
El bandidaje en el Estado de México durante el primer gobierno de Mariano Riva Palacio (1849-1852)
}

Laura Solares Robles

INSTITUTO MORA

\begin{abstract}
Este artículo presenta el panorama del bandidaje en el Estado de México durante el primer periodo de gobierno de Mariano Riva Palacio (1849-1852), la situación particular de la entidad, la administración de justicia y los caminos, así como un pequeño esbozo biográfico de este importante político. Estadísticas novedosas apoyadas en fuentes de primera mano localizadas en el Archivo General de la Nación complementan la información derivada de una pequeña parte de la correspondencia particular de dicho personaje.
\end{abstract}

EL BANDIDAJE EN EL MÉXICO DEL SIGLO XTX

$\mathbf{N}$ o obstante cuando se dieron innumerables intentos de acabar con el bandidaje durante los años de 1821 a 1869 , fue hasta el periodo presidencial de Benito Juárez cuando se dictó una ley para castigar a los plagiarios y salteadores (13 de abril de 1869) que daría los primeros resultados positivos contra un fenómeno tan importante. Sin embargo, no sería sino hasta el gobierno de Porfirio Díaz cuando esta ley se aplicaría con toda severidad, logrando acabar con bandi- dos de la talla de "Chucho el Roto", Heraclio Bernal, "El Tigre de Álica" y Santana Rodríguez, "Santanón", ejemplos reales en cuanto al empeño de eliminar este añejo problema. ${ }^{1}$ Durante la primera mitad del siglo XIX, el bandolerismo fue atacado mediante acciones concretas, sin mostrar estos logros positivos; no existían las condiciones adecuadas en el país en cuanto a estabilidad política y monetaria, para poder concentrar mayores esfuerzos económicos y humanos, para combatir

\footnotetext{
${ }^{1}$ Para abundar sobre el tema véase Solares,
} "Bandido", 1981. 
la delincuencia y en particular el bandolerismo, considerado endémico en toda la nación.

Resulta muy difícil cuantificar para entonces, cuántos de los delincuentes lo eran desde antes de que se iniciara la guerra de Independencia y cuántos se convirtieron en infractores a raíz y como consecuencia de ella; sin embargo, el bandidaje era ya un fenómeno bastante grave antes de esta fecha. El presente estudio intenta delinear un bosquejo aproximativo del bandidaje en el Estado de México, en los años que van de 1840-1850. Por ello, no abordaré el problema durante el periodo colonial a pesar de que ya existía ${ }^{2}$ y la atención se centrará en los años en que Mariano Riva Palacio dirigió los destinos del Estado de México por primera vez, apoyándome, entre otras fuentes, en la correspondencia de este personaje (resguardada en la Colección Latinoamerica de la Biblioteca de Texas en Austin, misma que comprende, demás de su correspondencia, documentos que van desde 1716 hasta 1880 ), seleccionando sólo las misivas que pertenecen al periodo de su primera gestión gubernamental (agosto 1849-mayo 1852). De importancia relevante resulta la información localizada en el Archivo General de la Nación pues muestra estadísticas del año de 1845, en cuanto a delincuencia y bandolerismo en particular.

Si bien uno a uno, los estados de la federación habían desplegado a partir

\footnotetext{
${ }^{2}$ Algunos estudios que refieren este problema durante el periodo colonial son: Mac Lachlan, Justicia, 1976 y Taylor, Embriaguez, 1987, entre otros.
}

de 1821, una importante actividad legislativa y humana para atacar a la delincuencia, ésta no disminuyó sino que se acrecentó poco a poco, debido a factores tales como la guerra independentista, la escasez generalizada de recursos en el erario y la multitud de pronunciamientos ocurridos durante este periodo hasta que, en la década de los cuarenta, llegó a límites considerables. Ello se debió, entre otros sucesos, a la guerra contra Estados Unidos, pues una vez concluida, todos aquellos hombres que habían participado como voluntarios o por prácticas como la leva, intentaban regresar a sus lugares de origen después de su actuación en el ejército. Y como no todos lo conseguían, ya encaminados en el uso y "abuso" de las armas, algunos decidían hacer fortuna antes de retornar al terruño valiéndose del robo o el pillaje o constituyendo las bandas que asolaron los caminos y las poblaciones.

Tratar de entender por qué el bandolerismo persistió a lo largo de casi todo el siglo XIX constituye un reto, y pueden sugerirse algunas de las causas que lo motivaron. Una de ellas se derivaba de la falta de educación, otra de la enorme pobreza y de la situación marginal de amplios sectores de la población a los que pertenecían todos aquellos que no tenían una fuente de trabajo estable, salarios suficientes para sostener a su familia y mucho menos un lugar propio para vivir. Algunas más sobrevinieron de la permanente inestabilidad política y económica de este periodo, y de ahí que el problema persistiera durante casi toda esa centuria. Y es que aunque el bandidaje no es consecuencia directa de un acon- 
tecimiento político o militar, o de un choque extraordinario como una invasión extranjera, la caída de un régimen o dinastía que ponga en peligro el sistema o régimen de un país, ${ }^{3}$ sí es una manifestación de crisis, de desorden debidos a problemas económicosociales que requieren evidentemente solución y que, aunados a crisis periódicas, como hambrunas o epidemias o ciclos interrumpidos de cultivo o cosecha, se conjugan para crear un ambiente propicio para la proliferación del bandidaje.

Hay que destacar que, aun cuando el bandolerismo está inserto en el campo de la delincuencia, presenta rasgos peculiares en cuanto a la comisión de la falta, pues no se considera un delito común -como podría serlo el crimen pasional, el uxoricidio, el parricidio o un incesto- sino que tiene su origen en causas político-económicas y sociales que marginan a grupos o individuos; éstos, al sufrir un trauma o una injusticia personal, aunados a la pobreza o el desprecio, deciden cometer un delito para resacirse de su situación inferior en el orden social y económico. Por ello, habrá que considerar al bandidaje como un

fenómeno endémico y permanente sin duda, pero por cierto no siempre igual. La primera observación que es preciso hacer tomando en consideración un panorama histórico amplio y secular, es que hay momentos en que el bandolerismo asume proporciones extraordinarias y masivas, un significado y una relevancia especiales. En esos momentos, el bandolerismo se distingue del

${ }^{3}$ Villari, Rebeldes, 1981, p. 85. pulular de casos que caen bajo la administración ordinaria. No se trata de una diferencia cuantitativa $[. .$.$] al llegar a$ ciertos límites se convierte en cambio cualitativo. $^{4}$

De hecho, el problema resultó tan grave durante la primera mitad del siglo XIX y parte de la segunda, que se legisló en particular contra las infracciones cometidas por los ladrones de camino o salteadores, como también se les denominaba, ${ }^{5}$ que son los principales actores en este artículo.

$Y$ es que el trabajo y la educación en los sectores de que provenían escaseaban, de ahí que delinquieran; por su parte, los hombres que gobernaban se encontraban tan ocupados en continuar sosteniendo una organización que les permitiera mantenerse en el poder, que descuidaron justo a aquéllos para quienes supuestamente trabajaban: los jornaleros, arrieros, labradores, gañanes, tejedores, carpinteros, albañiles y muchos más, es decir, la base de la pirámide social. Los hombres en el poder consideraban como prioritaria la tarea de hacer esa política pensando que con ello lograrían consolidar a la nación. Esto llevó a una larga lucha verbal en los foros y a otra no menos ardua manifestada en pronunciamientos, sublevaciones y asonadas, que mermaron considerablemente los esfuerzos debidos a atender ramos como los de justicia, educación, vivienda, salud y empleo; constante-

\footnotetext{
${ }^{4}$ Ibid., p. 87.

${ }^{5}$ Durante el periodo que va de 1821 a 1855 se decretaron por lo menos siete leyes sobre salteadores. La tesis doctoral de Laura Solares, "Bandidaje", 1997, abunda sobre el tema.
} 
mente, el erario nacional destinaba enormes recursos a sofocar pronunciamientos y revueltas, en lugar de a safisfacer las demandas de los sectores más numerosos. Tal como sucede en la actualidad, los recortes presupuestales incidían sobre todo en aquellos rubros que no se consideraban prioritarios, como la educación; con ello, las carencias de este sector se hacían cada vez mayores y sus consecuencias se apreciaban en los cientos de hombres orillados a una situación de pobreza más y más acentuada, al hecho de tener que sobrevivir día con día y a otra consecuencia inevitable: a iniciarse en las filas de la delincuencia, como única alternativa para mitigar las privaciones derivadas de una situación marginal impuesta por la sociedad a la que pertenecían.

Resulta oportuno mencionar que si bien el liberalismo pugnaba por la libertad del hombre, por sus derechos e igualdad ante los demás, según lo manifestaban sus más destacados defensores, la realidad que se vivía en México durante la primera mitad del siglo XIX, no correspondía a los ideales que se pretendian poner en práctica. Algunos liberales destacados, como José Ma. Luis Mora, consideraban indispensable que los hombres se educaran para tener acceso a dichas prerrogativas, sin embargo, la mayoría de ellos eran analfabetos. ¿Cómo entonces podían tener conocimiento de las leyes y de sus derechos? Los ideales no iban acordes con la realidad y, en algunos aspectos, estos liberales se contradecían en ese afán de imbuirse en la modernidad. Un ejemplo claro en cuanto al tema de la delicuencia, lo tenemos en el caso de Mora quien, influido por los estudios científicos contemporáneos consideraba, como muchos entonces, que los delincuentes poseían una "maldad innata" y que

apenas habrá cosa que haya sido más claramente demostrada en el estudio de las prisiones que lo hereditario del crimen $[\ldots]$ Por los testimonios recogidos y las observaciones hechas sobre la materia, el uno y la otra se transmiten de padres a hijos por una ancha y prolongada línea de sucesión. El único medio de hacer desaparecer estas plagas sociales sería la extinción progresiva. En efecto, si todos los criminales de la presente generación pudieran ser aprehendidos y colocados en una cárcel, los jóvenes para ser reformados y los viejos para pasar en ella lo que les queda de vida, la generación siguiente es bastante probable que no tendria sino muy pocos delincuentes [ya que] mientras un hombre permanece en prisión, no puede llegar a ser padre de delincuentes futuros $[\ldots]$ esta consideración es una razón grave e importante en favor de los encarcelamientos largos $y$ no interrumpidos $[\ldots]^{6}$

Ello explicaría, aunque sólo parcialmente, el carácter inhumano de la justicia, de las cárceles y en general del sistema judicial, pues consideraban al delincuente un hombre aquejado de "maldad", sin siquiera pensar en que existieran otras motivaciones, como la comisión del delito a consecuencia de las carencias económicas y del hambre. Por otra parte, ninguna de las cárceles de esta época intentaban reformar al reo, apenas sí contaban con un

\footnotetext{
${ }^{6}$ Mora, "Memoria", 1986, t. 7, pp. 69-73.
} 


\section{SECUENCIA}

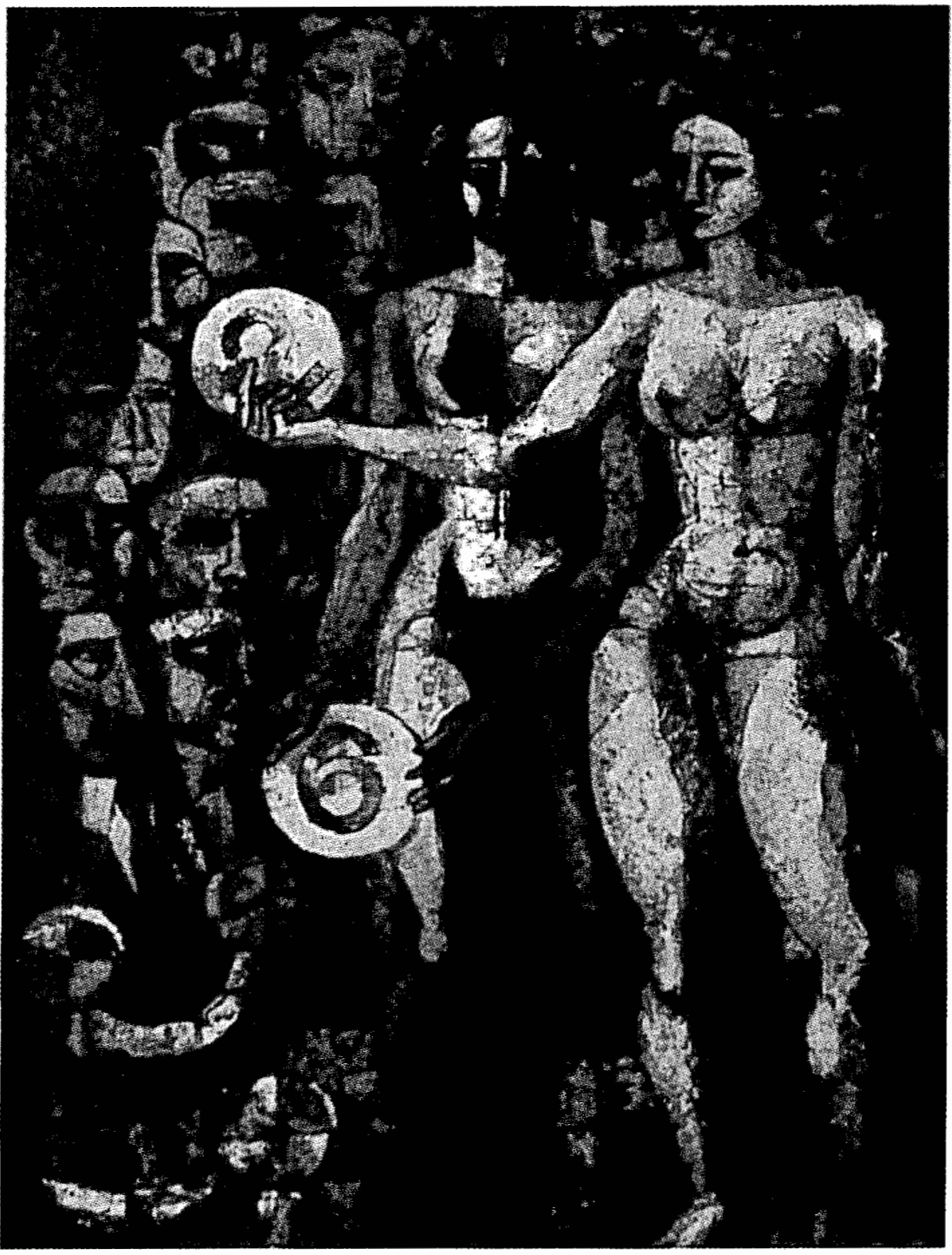


mínimo espacio para albergar a cientos de delincuentes que convivían hacinados con otros de mejores o peores circunstancias sociales y económicas, pero iguales ante un sistema judicial obsoleto, corrupto, lleno de vicios, de leyes incomprensibles y de alcaldes analfabetos igual que ellos. Estos seres privados de libertad y en espera de la conclusión de un proceso que resultaba a veces interminable, no sabían si finalmente se los conduciría a la libertad por falta de pruebas, a la condena en prisión o a la muerte por fusilamiento o decapitación, práctica por cierto común todavía hasta mediados del siglo XIX.

\section{LA ADMINISTRACIÓN DE JUSTICIA}

Uno de los principales retos a que se enfrentó el gobierno de la República en general, y los estatales en particular, lo constituyó la impunidad que se enseñoreaba de la administración de justicia. Por ello, el 6 de julio de 1848, el gobierno federal decretó una ley que

tenía como principal objetivo abreviar los juicios seguidos a ladrones, homicidas y heridores utilizando el recurso verbal y reduciendo el procedimiento a su mínima expresión. Además recurría a la pena capital en un intento por acabar con los infractores peligrosos. ${ }^{7}$

Esta ley sería aplicada en todo el territorio nacional, pues José Joaquín de Herrera, general de división y a la sazón presidente constitucional, de los Estados Unidos Mexicanos, consideraría:

\footnotetext{
${ }^{7}$ Solares, "Bandidaje", 1997, p. 368.
}

que habiéndose aumentado excesivamente en las poblaciones y caminos el número de malhechores, y convencido de que este desorden escandaloso emana principalmente de la impunidad, favorecida unas veces por la demora y prolongación casi indefinida de los juicios, y en otras por las dificultades que hoy ofrece en la averiguación de los delitos la falta de autoridades bastantemente facultadas, que por su inmediación a los lugares donde aquéllos se cometen ocurran con prontitud a justificarlos, aprehendiendo al mismo tiempo a sus perpetradores $[\ldots]]^{8}$

Resultaba preocupante el hecho de que, con demasiada frecuencia, se acusaba a los encargados de impartir justicia de ser los culpables de propiciar la delincuencia, y es que se sospechaba que algunos de ellos estaban coludidos con los bandoleros, les brindaban protección e incluso -se decía- participaban en actos delictivos. Esto sólo en parte era cierto, ya que también hubo hombres ejemplares encargados de impartir justicia que padecieron hambre y hasta miseria sin abandonar sus puestos por falta de pago de sus salarios. Nos referimos a los jueces letrados, quienes se ocupaban en los procesos de los expedientes, en segunda y tercera instancia, para confirmar la sentencia dictada por la primera instancia, o sea el alcalde, en la mayoría de los casos analfabeto.

Muchas menos consideraciones merecen estos alcaldes encargados de iniciar los procesos y que constituían el primer contacto del delincuente con la autoridad al momento del delito.

${ }^{8}$ El Siglo Diez y Nueve, 9 de julio de 1848. 
Ellos, que ocupaban inexplicablemente puestos de trascendental importancia, desconocían las leyes y, como es obvio, el modo de aplicarlas. Las consecuencias de esto se apreciaban en que, desde el momento de iniciarse el proceso a un delincuente y de abrirle un expediente penal, éste contenía defectos, omisiones o incongruencias que sólo apreciaban los jueces letrados y que llevaban a que el juicio se prolongara indefinidamente al no dictarse sentencia en el plazo marcado por la ley o bien, que se declarara libre al infractor por falta de pruebas "claras como la luz del día". Debido a esta situación, una enorme cantidad de hombres esperaban sentencia en las cárceles del país y otros sólo aguardaban la primera oportunidad para fugarse y reintegrarse a las filas de la delincuencia, pues era común que en la misma cárcel, algunos delincuentes se asociaran y prepararan el siguiente golpe.

Aunque el problema del bandidaje se derivaba parcialmente de la época colonial, nos interesa resaltar el punto de vista que respecto a esta situación formularía Lucas Alamán en 1830, en la Memoria estatal correspondiente y en el apartado destinado a informar sobre Tranquilidad Pública, al señalar que:

la seguridad personal y de las pro. piedades tiene una conexión inmediata con la tranquilidad pública, pues todo el que turba ésta pone en peligro aquéllas[...] sólo una administración vigorosa y severa de la justicia puede corregir estos males; pero el espíritu de partido se interpone y enerva la fuerza de la ley. $\mathrm{Si}$ a estas causas generales se agregan las particulares que expondrá el señor secretario de Justicia [...] acerca de la defectuosa organización de los juzgados, de la carencia de medios para actuar en lo criminal, de la poca seguridad y ninguna comodidad de las cárceles en general, se extrañará menos la frecuencia con que criminales conocidos públicamente como tales, muchas veces aprehendidos y puestos ante los jueces, han salido libres a perpetrar mayores delitos, con la confianza que les inspira la falta de castigo. Añádase la frecuencia de los indultos y la facilidad con que se conmutan las penas y se formará una idea cabal de la impunidad con que cuenta el crimen $[\ldots] .{ }^{9}$

Esta temprana apreciación seguiría siendo válida para las décadas siguientes hasta la llegada de Porfirio Díaz al poder, ya que la administración de justicia, la aplicación de las leyes y el estado lamentable de las cárceles en todo el país no se modificaron de ningún modo. Por el contrario, conforme fue avanzando el siglo, las condiciones de inseguridad pública se acentuaron y el retraso en la aplicación de la justicia por errores, la mayoría de las veces imputables a los alcaldes, fue cada vez mayor: la falta de unidad y claridad en cuanto a la legislación operante (que mezclaba leyes coloniales con las de orden federal recientes y las estatales correspondientes) convirtieron al aparato legislativo en una maraña difícil de interpretar hasta por los más capacitados. Como consecuencia de estos factores, la impunidad se impuso sobre las sentencias, pues los delincuentes rara vez resultaban condenados y, si lo eran, las penas impuestas no siempre iban acordes con el delito cometido.

\footnotetext{
${ }^{9}$ Alamán, Memoria, 1830, p. 16.
} 
El baNDIDAje EN El EsTado DE MÉxico

El bandidaje estaba asociado a otro elemento de vital importancia: los caminos. La escasez y el descuido en el mantenimiento de las rutas de comunicación, en estas primeras décadas del México independiente, incidía de manera fundamental en la vida económica del país, pues en su mayoría estaban deterioradas, se consideraban inseguras, no contaban con servicios adecuados para proporcionar en sus trayectorias albergue y comida a los transeúntes y en épocas de lluvia se volvían intransitables. Todo ello era convenientemente aprovechado por los salteadores de caminos, quienes convertían estas situaciones desfavorables para quienes los transitaban, en favorables para la comisión del delito.

En el caso particular del Estado de México, ya desde 1835, el gobierno reconocía la existencia de dichas condiciones y manifestaba su preocupación al considerar que ellas determinaban, en buena medida, los movimientos económicos y poblacionales en el territorio. A este respecto señalaba:

Exceptúense las pocas poblaciones y haciendas que están sobre las rutas carreteras que contiene el estado y las inmediatas a los embarcaderos de Chalco y Texcoco, y todas las demás del Estado ya tienen que vencer obstáculos, muchas veces insuperables, para poder rivalizar con sus frutos en los mercados principales. Aun los caminos existentes son tan malos en lo general, que no hacen practicables los transportes, sino a lomo de mula y jumentos[...]. ${ }^{10}$

10 [Varela] Memoria, 1835, citado en Moreno, "Estado", 1993, pp. 73-74.
Y es que a través del territorio mexiquense se conectaban las principales vías que iban de norte a sur y de oriente a occidente del país; el camino más importante por su tamaño era el que lo surcaba al oeste hacia Michoacán y llegaba hasta Tepetongo pasando por Toluca; hacia el sur, estaba el que conducía a la ciudad de Cuernavaca y el que llegaba a Achichipico por un camino carretero, para después convertirse en uno de herradura. La comunicación hacia el sur era más complicada, pues básicamente se realizaba a través de caminos de herradura, a ello se sumaba la accidentada geografía de la región, con lo cual, se tenía una zona prácticamente aislada del resto del estado. ${ }^{11}$ Dentro de sus rutas destacaban las de Toluca, Cuernavaca, Tulancingo y Taxco; las dos primeras por cierto, frecuentemente asoladas por el bandidaje que, de forma casi intuitiva, se asociaba a los lugares de mayor movimiento comercial y poblacional, es decir, donde había más dinero o productos que pudieran redituar ganancias.

Dentro de los linderos estatales, especialmente en la región central, estaba concentrada la mayor parte de las haciendas más ricas en ganado, granos, azúcar, así como las que cultivaban naranja, plátano y otras frutas tropicales. También tenía algunas de las minas de plata más importantes, entre las que destacaban Taxco, Sultepec, Temascaltepec, El Oro y Real del Monte. Por si esto fuera poco, era el estado más populoso de la república y en Toluca tenía a la segunda ciudad más importante después de la de México. Go-

${ }^{11}$ Moreno, "Estado", 1993, p. 112. 


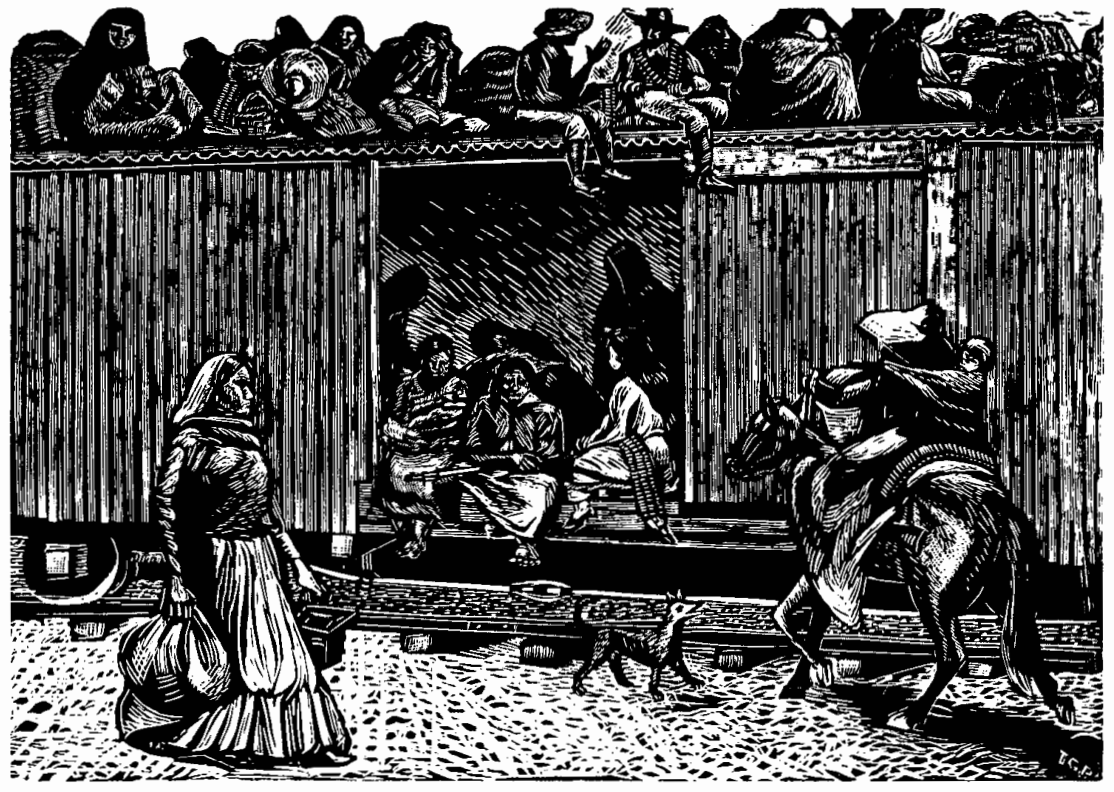

bernar al Estado de México resultaba bastante complicado debido a sus dimensiones, pues era una de las entidades más grandes y colindaba con varios estados (San Luis Potosí, Veracruz, Puebla, Tlaxcala, Oaxaca, Michoacán, Guanajuato y lo que después serían Hidalgo, Querétaro, Morelos y Guerrero), lo que de por sí originaba incontables problemas relacionados con la posesión de la tierra y, por otra parte, lo convertía en paso obligado para dirigirse hacia diversos puntos de la república.

Su posición geográfica se complicaba aún más por el hecho de tener incluidos dentro de su territorio al Distrito Federal y a la capital del país, con- siderada su centro político, comercial, religioso, intelectual y social. Allí se localizaban, además del gobierno del estado, el poder ejecutivo nacional, sus secretarías y respectivas burocracias, el Congreso y los tribunales superiores, entre otras dependencias, todo lo cual se traducía en un enorme poder político que rivalizaba con el estatal. El mercado más grande e importante de la nación realizaba ahí sus operaciones para el resto de los estados y del mundo. Todo ello hacía de la entidad un lugar muy apreciado para llevar a cabo actividades productivas legales e ilegales. De ahí también la proliferación del bandidaje y la persecución de que eran objeto los delincuentes. 
La desafortunada situación de las vías de comunicación del Estado de México y en general de la república, perduró a lo largo de la primera mitad del siglo XIX, según lo confirmaría la prensa en un artículo publicado el 30 de junio de 1848, titulado "Inseguridad de los caminos" en donde se señalaba que, entre las causas que contribuían eficazmente al desarrollo y progreso del comercio interior, de la agricultura y de "todas las artes útiles y necesarias", debían contarse la facilidad y prontitud en las comunicaciones. Sin embargo, en el país éstas eran difíciles por el mal estado material en que se encontraban los caminos y por la inseguridad que, de modo alarmante, los afectaba. De ahí que,

el estado de inseguridad en que actualmente se encuentran nuestros caminos públicos, hace que apenas se vean transitados por los que tienen imprescindible necesidad de hacerlo; de esta manera, el comercio y la agricultura sufren notables perjuicios $[\ldots]$ el labrador y el comerciante prefieren tener guardados sus frutos y mercancías, o mal venderlos de la manera que les es posible, a transportarlos a otros puntos casi con la certeza de perderlos, y exponiendo sus vidas a peligros inminentes $[\ldots]$ [como no se puede contener a los ladrones] en los caminos públicos, en los que para asegurar muchas veces el éxito de su rapacidad no desprecian los medios de los asesinos. Tanto más se hace necesaria una escrupulosa vigilancia en aquéllos, cuanto que los ladrones escogen para perpetrar sus robos los lugares en que menos es posible a los pasajeros esperar algún auxilio [...] Hay pueblos en los que todo el mundo está al alcance de que tales o cuales perso- nas se mantienen de robar, se sabe a punto fijo las horas en que salen a sus expediciones, los lugares ordinarios de los asaltos $[\ldots]$ se sabe todo lo concerniente a sus vidas $y$ acciones, $y$ a pesar de esto nadie los delata y ellos viven con tanta seguridad y confianza cual la que disfruta el hombre laborioso que tiene la conciencia de ser útil a sí mismo y a la sociedad en que vive[.... ${ }^{12}$

El diario agregaba que la mayoría de los habitantes esperaba la acción pronta y decidida de las autoridades en la creación de una buena policía rural para acabar con la multitud de malhechores que asolaban los caminos. Los deseos de los ciudadanos se hicieron realidad durante el año de 1849 , ya que la mayor parte de las en. tidades autorizó la formación de cuerpos rurales que proporcionaran seguridad, sobre todo en las vías asoladas por las gavillas. Así, cuando Mariano Riva Palacio asumió la gubernatura del Estado de México en agosto de 1849, tenía en sus manos los elementos para dar un ataque frontal a los bandidos.

${ }^{12}$ El Siglo Diez y Nueve, 30 de junio de 1848. De hecho, el 31 de mayo de $1848 \mathrm{el}$ gobierno habia decretado el establecimiento de fuerzas de seguridad pública, formadas por vecinos del estado. En este decreto se reglamentaba el que "todos" los habitantes estaban obligados a contribuir con su persona y armas a la seguridad de las poblaciones y caminos dentro de los límites de su municipalidad. Incluía a sujetos entre los 18 y los 50 años. La norma también contemplaba que las causas de ladrones en cuadrilla formadas por cuatro o más malhechores deberían conciuirse por jueces de primera instancia en el término de 15 días. Ellos en un intento por agilizar la administración de la justicia. Véase Colección, 1850, t. ul, pp. 172-177. 
Casi de inmediato, el 13 de octubre del mismo año, decretó una ley que creaba la policía rural; con ella, obligaba a todos los arrendatarios y hacendados a proporcionar hombres y recursos pecuniarios para conformarla. Su acción resultó tan eficaz, que en algunos puntos del estado, como Apam, Calpulalpan, y Cuernavaca, disminuyó radicalmente la comisión de delitos por robo. ${ }^{13}$

Esto parece confirmarlo la correspondencia a la que hemos hecho referencia -de fecha anterior a que se decretara la ley-, donde se mencionan constantemente las acciones emprendidas por diversos grupos, como el que lideraba Agustín Cruz, quien comunicaba a Riva Palacio, el 27 de septiembre de 1849, que había manifestado al comandante sus instrucciones

para mandar la caballería a los pueblos para perseguir las gavillas que se [vayan] presentando; pero me dice que una gavilla que ha quedado en el monte es de 80 a 100 hombres y que divisando venir otra de Cuernavaca, es exponer tanto las fuerzas de caballería del estado, como las del ejército y que también se expondría este punto [...] Yo he mandado correos [...] a los alcaldes [...] para que tomen las noticias posibles $y$ nos informen para dirigir la fuerza adonde convenga $[\ldots]$ Al destacamento de las Cruces nos lo dispersó una gavilla grande $[. .$.$] remití a usted a todos los$ sospechosos que hemos encontrado y de los informes tomados en el viaje, resulta que esos hombres no pasaron por Cuajimalpa. Uno que era empleado y se apellida Armas, que también remití,

${ }^{13}$ González, Anatomia, 1977, p. 124. vino seguramente de espía mandado de Toluca para ver si venía la tropa, o a hablar por el monte con los ladrones [...] seguiré comunicando a usted todo lo demás que ocurra $[. ..]{ }^{14}$

La misiva refleja los esfuerzos encaminados a acabar con el bandidaje, pero también la eficacia de los bandoleros en cuanto a su capacidad de organizarse en gavillas bastante numerosas y ubicar espías en lugares estratégicos (aunque en ocasiones no resultaran tan efectivos). Los bandidos no descansaban a pesar de las persecuciones de que eran objeto por parte de las fuerzas destinadas en diversos puntos del estado. Así lo informaba Francisco Murphy a Riva Palacio el 29 de septiembre, al señalar que la conducta proveniente del mineral de El Oro se hallaba detenida en Ixtlahuaca "a causa de una gruesa partida de ladrones que la querían robar" y que el conductor no se decidía a continuar el camino porque "la escolta que trae es poca para hacer frente a tanto ladrón".15

${ }^{14}$ [Comunicación de Agustín Cruz a Mariano Riva Palacio], 27 de septiembre de 1848 , en el microfilm del Archivo de Mariano Riva Palacio, en poder del Instituto Mora y que se encuentra originalmente en la Colección Latinoamericana Nettie lee Benson, de la Universidad de Texas en Austin (en adelante se citará como BLAC) más el número correspondiente de la misiva, BLAC, 3191.

is [Carta de Francisco Murphy a Mariano Riva Palaciol, 29 de septiembre de 1849, en BLAC, 3205. La preocupación de Murphy respecto a la posibilidad de un asalto estaba bien fundamentada ya que de El Oro, sacaba [isemanalmente?] entre 30000 y 40000 pesos en mineral de oro y plata. Algunas fuentes periodísticas revelaban en octubre de ese año que llegaba a mandar conductas con 100000 pesos que ocultaba 
La preocupación por la delincuencia y, en particular, por el bandidaje en los caminos -y en especial, en los mexiquenses- era compartida por los ministros del gabinete de Herrera, en este caso por Mariano Arista, quien desempeñaba la cartera de Guerra y Marina y le informaba a su "querido amigo y compañero" Riva Palacio, que "[...] el camino entre Temascaltepec y Toluca está plagado de ladrones que se guarecen en el monte, y [confiamos en que] la fuerza de León, servirá para limpiar el país de esa canalla[...]"16 En efecto, la misma correspondencia indica que los capitanes de rurales apellidados León y de nombres Francisco y Esteban, desplegaban una enorme actividad por diversos puntos del territorio mexiquense. Sin embargo, los bandoleros no respetaban ni clase ni condición social para cometer sus atracos, como lo informaba José del Villar al gobernador Riva Palacio desde Coyoacán, el 30 de enero de 1850 , contándole que,

el día 28 en el monte del Desierto, una cuadrilla de veinte y tantos de Acupilco asaltó a unos maiceros del rancho de Almoya [¿Almoloya?]. Los robó, mató a tres e hirió a otros varios. Ya estan presos 19: hay algunos confesos y voy a concluir las causas velozmente, pues tengo ganas de hacer un buen escarmiento $[\ldots] .{ }^{17}$

al gobierno para evadir impuestos. Para más detalle véase Staples, Bonanzas, 1994, p. 131.

${ }^{16}$ [Correspondencia particular del ministro de Estado y del Despacho de Guerra y Marina al E. S. gobernador don Mariano Riva Palaciol, 17 de octubre de 1849, en BIAC, 3293.

${ }^{17}$ [Carta de José del Villar a Mariano Riva Palacio], 30 de enero de 1850, en BLAC, 3795.
El hecho de que los bandoleros no respetaran la condición social de sus víctimas, resultaba un denominador común al resto de los maleantes que asolaban al país por esa época; en los caminos no había salvación ni para un sacerdote, quien obligado por su desempeño a asistir a otros lugares para dar la extremaunción, se convertía en víctima de robo por parte de los bandidos, y tampoco respetaban a los hacendados. Por el contrario, éstos se convertían en sus proveedores y ocasionalmente eran víctimas de chantaje, pues a cambio de una suma, los forájidos se comprometían a "respetar" sus propiedades. Algunos estados como Querétaro, de importancia relevante por sus grandes haciendas productoras de cereales y de ganado bovino y caprino, habían solicitado protección legal al Congreso local para atacar al bandidaje. En una misiva fechada el 19 de septiembre de 1849, Luis Rovalo, un prominente comerciante, le comunicaba a Riva Palacio que

le parecía oportuno poner en su conocimiento que, según se ve en $E l$ Siglo Diez y Nueve de ayer martes 18 , el Congreso de Querétaro por un decreto que ha dado, ha autorizado a los propietarios de aquel estado, para que a sus expensas levanten, armen y organicen las fuerzas de infantería y caballeria, que juzguen necesarias, para defender sus haciendas de las gavillas de malhechores que las invaden $[\ldots] .{ }^{18}$

Tal vez, los comerciantes afectados por el bandidaje -entre ellos Rovalo-

${ }^{18}$ [Comunicación de Luis Rovalo a Mariano Riva Palacio], 19 de septiembre de 1849 , en BIAC, 3161. 


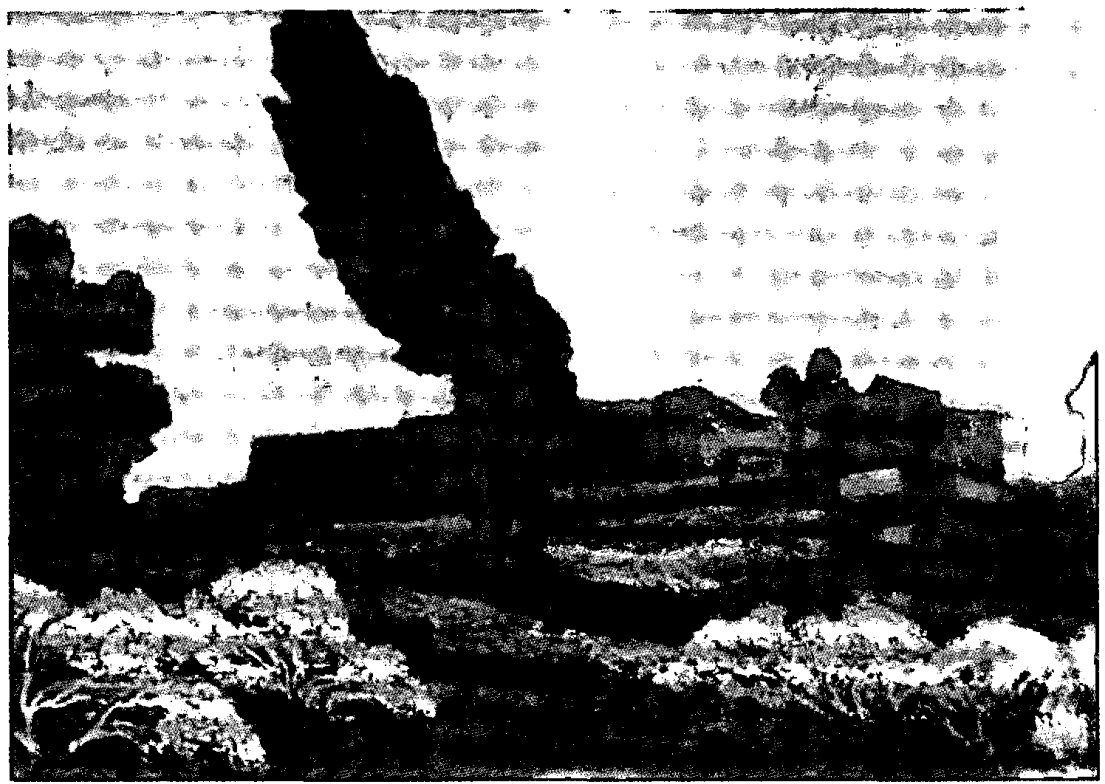

presionaban al gobernador para que dictara leyes precisas para contener la epidemia. Y es que el bandidaje rebasaba los límites de la atención que el estado podía dispensarle, a tal punto, que los ciudadanos comenzaron a proponer $\mathrm{y}$ a hacer efectivas medidas de protección personal y, en algunos casos se tomaron la justicia por su mano. La inseguridad que se vivía en los caminos, se pudo apreciar también en el caso de los diputados que se habían trasladado a Querétaro para cumplir con sus labores legislativas ante la ocupación de la capital por los soldados estadunidenses. De hecho, cuando llegó el momento de regresar a la ciudad capital,

El bandidaje en El ESTAdo de MÉxico las familias de los señores diputados que se hallaban en Querétaro, [tuvieron] que señalar un día para su salida y hacerlo reuniendo coches en caravana, y además, muchos individuos a caballo que con la escolta que venía formaban un número de más de 600 personas... [El informativo se preguntaba] " $i D o ́ n d e$ iremos a parar si en todo el país se necesita de este arbitrio para transitar por sus caminos?"19

El bandolerismo alcanzaba también a los empresarios, sobre todo a aquéllos dedicados al ramo de la comunicación como Anselmo Zurutuza, quien desde la década de los años treinta,

${ }^{19}$ El Siglo Diez y Nueve, 22 de junio de 1848. 
había participado en la creación de distintas líneas de diligencias que recorrían de norte a sur y de este a oeste los caminos de la república mexicana. Asociado a Manuel Escandón explotaba las rutas hacia Toluca, Querétaro, Puebla y Veracruz; ninguna de ellas se había salvado de los asaltos, a tal punto, que la de Puebla había sufrido, en un sólo día, trece veces el embate de los salteadores, razón por la cual, los pasajeros ya no querían viajar en ellas. Si bien algunos caminos resultaban más afectados por los maleantes debido a su importancia comercial, el que presentaba mayor incidencia de asaltos era el de México a Veracruz. La misiva que a continuación se presenta y que forma parte de la correspondencia de Mariano Riva Palacio, da una idea muy clara de la situación hacia marzo de 1850:

Venta de Córdoba [...] señor Anselmo Zurutuza [...] México [...] estoy bien filiado de todos los malhechores que disfrazados pasan, y tal vez yo no los conoceré, como en efecto hace algunos días que en una de las diligencias pasó un ladrón con traje decente, al observar de qué modo se custodia el camino, cuya noticia tuve yo hasta los diez días por un compadre mío que se fue para Jalapa; y yo deseo que vuelva para alambicar bien el asunto, a más de esto, a usted le conviene favorecernos en punto al sostén de la comisión que tenemos, para que en cualquier encuentro que tengamos con los salteadores, podamos ejecutar un ejemplar con algunos de los que sean más afortunados; ellos no le temen a Dios ni le piden permiso a la justicia de la sierra para matar a cualquier infeliz pasajero, todo lo hacen a rigor de las armas: roban, asesinan, es- tupran, golpean, y hacen lo que quieren en su temible tribunal $[. .$.$] estos$ hombres estoy cierto que es más fácil majar hierro y darle dormitorio a un muerto que ellos se enmienden [...] José Ma. Alvarado de Lara[... ${ }^{20}$

Resulta muy interesante conocer la táctica de los bandidos -similar en este tipo de atracos a la de otras entidadespara sortear los peligros y observar cómo se valían de disfraces y cómo reconocían la ruta sin ser detectados para luego robar a los pasajeros. Muy probablemente, esta misiva haya sido enviada a Mariano Riva Palacio por el mismo Zurutuza para darle una idea de la situación por la que atravesaba su empresa y de las medidas que algunos ciudadanos sugerían para remediar la inseguridad en los caminos. El gobernador ya estaba al tanto de estos pormenores, pues la entidad mexiquense no se libraba de los salteadores, quienes asociados a reos prófugos, podían formar gavillas bastante numerosas. Así lo daba a conocer Agustín Cruz al gobernador Riva Palacio desde Tenango, el 6 de abril de 1850 , en un comunicado donde le señalaba que los bandidos:

[...] siguen robando en este rumbo de Calimaya de una manera escandalosa y los prófugos de la cárcel de esta villa forman parte de la gavilla. Dios quiera que el día menos pensado no nos reúnan una partida de 200 o más [...]. ${ }^{21}$

${ }^{20}$ [Carta de José Ma. Alvarado de Lara a Anselmo Zurutuza], 25 de marzo de 1850 , en BLAC, 4022.

${ }^{21}$ [Comunicación de Agustín Cruz a Mariano Riva Palaciol, 6 de abril de 1850, en BLAC, 4044 . 
Esta información alarmante sobre, el bandolerismo estaba bien fundamentada porque, en efecto, llegaba a asociarse un gran número de hombres conformando gavillas hasta de más de 200 integrantes en diversos puntos del país; por contraste, también se presentaban informes donde la situación se apreciaba menos grave, tal era el caso del reporte que Francisco Herrera y Campos le enviaba a Riva Palacio desde Texcoco donde suponemos era prefecto. En éste le señalaba que,

por lo que toca a seguridad, pues lo que usted me dice sobre este punto, me hace entender no le han dado cuenta con mis repetidas comunicaciones en que he probado la falsedad de esa repetición de robos de que hace alharaca el gobierno y los periódicos; pues los que han ocurrido, bien claro lo expresan los informes de los alcaldes de los pueblos que están en el camino, [son] debidos no a la falta de cuidado de los quince hombres que lo custodian, sino a la imprudencia del mayordomo o administrador de los carros, que salen a horas que la fuerza debe estar en descanso, que son las dos, tres o cuatro de la mañana o porque se han verificado en el territorio de Puebla, de los que no se puede culpar... [a este gobierno]. ${ }^{22}$

Sin embargo, la realidad expuesta en diversas publicaciones, así como en las Memorias de gobierno y en la correspondencia personal de Riva Palacio, señalan que el bandidaje resultaba más complicado de lo que quería aparentar el prefecto, pues no se debía a

${ }^{22}$ [Comunicación de Francisco Herrera y Campos a Mariano Riva Palacio], 22 de agosto de 1850 , en BLAC, 4613.

El bandidaje en el Estado de MÉxico que las diligencias fueran asaltadas por salir en la madrugada, sino que los asaltos en el camino y los robos en general proliferaban por todo el territorio nacional. ${ }^{23}$ Un ejemplo que contrasta con el reporte de Herrera y Campos, es el dirigido por Luis A. Alcocer desde San Pablo al gobernador, en donde le manifestaba su evidente preocupación como sigue:

[...] Ya nos comen los ladrones, no hay noche que no se verifiquen robos de todo género, los más de los ladrones son de [Tenancingo] y Zumpal[huacán] donde se pasean a ciencia y paciencia de los jueces, porque a esto los ha reducido la impunidad, pues no hay ladrón que dure ocho días en la cárcel. ${ }^{24}$

Y si bien es cierto que la impunidad se enseñoreaba de casi todo el territorio nacional, también había autoridades que cumplían eficazmente su labor como el comandante Esteban León, quien desde Temascaltepec le informaba que,

con demasiado interés se persigue a los malhechores, y se escarmientan de la misma manera; pues que la fuerza de seguridad pública que tengo a mis

${ }^{23}$ Para más información sobre asaltos en el territorio mexiquense pueden verse: $E l$ Siglo Diez y Nueve, 14 de febrero y 25 de mayo de 1845; El Republicano, 31 de octubre de 1846 y 8 de enero de 1847; El Monitor Republicano, 6 de noviembre y 17 de octubre de 1847; El Eco del Comercio, 27 de marzo de 1847 y El Siglo Diez y Nueve, 16 y 27 de agosto de 1848. En estas publicaciones abunda la información sobre el mismo tipo de delitos en otros estados.

${ }^{24}$ [Correspondencia de Luis A. Alcocer a Mariano Riva Palacio], 28 de octubre de 1850 , en BLAC, 4808. 
órdenes ha fusilado en la plaza de este mineral a las 10 del día 17 del corriente, a los ocho criminales que asaltaron en la Agua Bendita, por haber confirmado la sentencia la 2a. sala del Tribunal Superior del estado: todo lo que de oficio comunico a usted con esta misma fecha, y sólo de esta manera conseguiremos extinguir la multitud de perversos que pretenden vivir del trabajo de los ciudadanos pacíficos $[\ldots]{ }^{25}$

El interés en las autoridades sería reforzado, probablemente, por la aplicación del decreto estatal del 11 de octubre de 1849, en donde se establecía la pena de muerte para los responsables de delitos de robo calificado considerados para efectos de esta ley,

los cometidos en despoblado por gente armada, mediante muerte, herida grave, por esencia o forzamiento de mujer; los cometidos en poblado o despoblado por cuatro o más personas, si alguna fuese armada, aun cuando no haya muerte ni herida; los que se cometieran entrando por fuerza en las habitaciones, haciendas, edificios que sirvieran a la administración pública, iglesias o lugares religiosos $[\ldots]^{26}$

${ }^{25}$ [Esteban V. León a Mariano Riva Palacio], 21 de diciembre de 1850, en BLAC, 4919.

${ }^{26}$ Colección, 1851, t. IV, y Sánchez, Legislación, 1975, t. 1, p. 64. El Estado de México al igual que las demás entidades que conformaban al país, legislaron de manera específica leyes locales que tomaban algunos puntos de las federales, tal es el caso de ésta que contiene algunos puntos ya mencionados en la ley federal del 27 de septiembre de 1823 , acaso una de las más rigurosas y la primera de las que se dictaron durante el periodo posindependiente en donde se contempló por vez primera la pena de muerte para los salteadores de caminos o ladrones en despoblado.
Y es que la situación de algunas gavillas, en cuanto a disponibilidad de armas y otros recursos, no era favorable a las autoridades, pues había algunas que además de ser numerosas se encontraban bien relacionadas (probablemente hasta protegidas) y perfectamente montadas. Ello nos hace suponer que los habitantes de los poblados las favorecían acaso brindándoles escondite o provisiones. Esto resultaba común también en otras entidades, en donde la población se volvía cómplice de las gavillas mediante amenazas o bien porque la proveían de algunos satisfactores elementales compartiendo parte del producto del pillaje, una actitud considerada por estudiosos como Eric Hobsbawm, como de identificación entre sectores desprotegidos $y$ humillados por la misma sociedad. A este respecto Hobsbawm señala:

El hecho crucial de la situación social del bandido es, efectivamente, su ambigüedad. Es un marginado y un rebelde, un pobre que se niega a aceptar las pautas normales de la pobreza y que establece su libertad con los únicos recursos que están al alcance de los pobres: la fuerza, el valor, la astucia y la determinación. Esto lo aproxima a los pobres, es uno de ellos y lo opone a la jerarquía del poder, de la riqueza y de la influencia: no es uno de ellos [...] es "uno de nosotros" sometido constantemente al proceso de verse asociado con "ellos". Cuando más triunfa como bandido, más resulta un representante y campeón de los pobres, a la vez que una parte integrante del sistema de los ricos. ${ }^{27}$

${ }^{27}$ Hobsbawm, Bandidos, 1976, pp. 106-107. 
Desafortunadamente para los historiadores, aún no contamos con el testimonio de esa parte fundamental del estudio del bandidaje: el del hombre al margen de la ley. Desconocemos sus argumentos porque la historia ha conservado solamente la parte escrita correspondiente a la autoridad, a la justicia, por lo cual, cualquier estudio relacionado con el tema no deja de ser parcial e incompleto. Ante estas circunstancias, resulta de fundamental importancia utilizar fuentes de primera mano, como las existentes en el Archivo General de la Nación. Algunas de ellas me permitieron conocer de una manera aproximativa, la situación de la delincuencia hacia $1845 \mathrm{y}$, en particular, la del Estado de México, una entidad muy especial.

\section{EL HOMBRE}

Era lógico que, entre los numerosos personajes que dirigieron el rumbo de la nación en las primeras décadas del siglo XIX, hubiera alguno que, en particular, hubiera atendido las necesidades de una entidad tan compleja como el Estado-departamento de México. Y al parecer, nadie tan apropiado como Mariano Riva Palacio: hijo de Esteban Riva Palacio y Dolores Díaz, había nacido en la ciudad de México el 4 de noviembre (hay quien señala que la fecha fue el 26 de julio) de 1803. Como hombre representativo de su época, había elegido convertirse en abogado (las otras opciones eran el sacerdocio o la milicia); sin embargo, desconocemos las razones por las cuales no llegó a concluir los estudios necesarios. Lo que sí sabemos es que provenía de una familia con recursos económicos suficientes para proporcionarle una carrera, situación que por cierto era un privilegio reservado sólo a ciertos sectores de la población. ${ }^{28}$ Hacia 1829 ya era regidor del Ayuntamiento capitalino, lo que nos hace suponer que le atraía la tarea político-administrativa. Desafortunadamente, este destacado político decimonónico no ha sido rescatado ni valorado en su justa dimensión y lo poco que sabemos de su vida personal y pública se ciñe a algunos datos todavía inconexos: ocupó una curul como diputado de 1833-1834 y, posteriormente, alternó más de doce veces la diputación y la senaduría en el Congreso de la Unión; fue además ministro de Justicia y de Hacienda en diferentes momentos en el gobierno de José Joaquín de Herrera; fungió como gobernador del Estado de México en tres ocasiones, como veremos más adelante, para luego desempeñarse como diputado al Congreso Constituyente en 1856. En ese año, formó parte de la Junta del Desagüe del Valle de

${ }^{28}$ Según Jack Autrey Dabbs, compilador de la Guía del Archivo de Mariano Riva Palacio situado en la Universidad de Texas, Mariano Riva Palacio era poseedor de una hacienda cercana a la ciudad de México, las misivas contenidas en el archivo mencionan por lo menos otras dos de su propiedad; sin embargo, se desconoce si llegaron a sus manos como legado de una herencia. De todas formas las continuas referencias a las actividades de cultivo, cosecha y venta de las mismas nos hacen suponer que por lo menos poseía bienes que le redituaban un ingreso regular, si no es que cuantioso. Las haciendas en cuestión eran la de La Asunción, la de San José de Chalco y la de San Nicolás del Moral. Véase Dabbs, Mariano, 1967. 
México y fue vocal de la Junta de Crédito Público. En 1863 rechazó formar parte de la Junta de Notables y, con el emperador Maximiliano, se negó a ocupar la cartera de Gobernación; no obstante, en 1867, al caer prisionero éste, lo nombró su defensor. Su carrera política y su amor al país lo llevaron a dirigir de nuevo el Ayuntamiento de la ciudad y a ocupar la presidencia de la Cámara de Diputados en 1868. En 1871, encabezó la Junta Menor Directiva para la desecación de las lagunas del río Lerma. En su último cargo público, se desempeñó como director del Nacional Monte de Piedad hacia 1876. Y su muerte, acaecida en su ciudad natal, le sobrevendría el 20 de febrero de 1880 a los 77 años de edad.

Mariano Riva Palacio gobernó el Estado de México en varias ocasiones: de agosto de 1849 a mayo de 1852 , de enero a julio de 1857 y de septiembre de 1869 a abril de 1870 . En las tres ocasiones pretendió dar un impulso renovador a la entidad con diversas medidas de orden económico y administrativo; nos interesa destacar la primera de sus gestiones donde inició un ataque frontal al bandolerismo.

La correspondencia particular de este personaje, resguardada en Austin, Texas, nos da una idea aproximada de sus relaciones personales y políticas. Entre los personajes con quienes mantuvo vínculos epistolares se encontraron Lucas Alamán, Mariano Paredes y Arrillaga, Antonio Haro y Tamariz, Juan Álvarez, Ignacio Comonfort, Benito Juárez, Sebastián Lerdo de Tejada, Manuel Gómez Pedraza, Mariano Otero, Mariano Arista y José Joaquín de Herrera, entre otros. Pero no sólo figuras de esta talla lo consultaban y pedían opinión sobre asuntos personales y de política: muchos hombres de diferente extracción se mantuvieron cerca de él, y es que Mariano Riva Palacio siempre estuvo rodeado de personajes, sin importar que fueran liberales o conservadores, la filiación política más común entonces; algunos de ellos lo consideraban moderado. En este sentido, podemos aventurar que hay un rasgo de su personalidad que lo acerca significativamente a este grupo, y es que siempre rehusó el uso de la fuerza y la violencia como solución a algún problema; de hecho, es probable que se identificara hacia 1838 con Manuel Gómez Pedraza, líder de los moderados, quien en un intento para retomar la Constitución de 1824 y con ello el régimen federal, pedía al Congreso participar en una "revolución filosófica", es decir pacífica, un planteamiento propio del grupo moderado y muy significativo de su orientación en cuanto a la manera de hacer los cambios.

Debido a la falta de estudios sobre Riva Palacio en particular, y sobre los moderados en general, resulta importante destacar algunas de sus relaciones personales, ya que a través de ellas, podemos rastrear su desempeño en diferentes momentos de su actividad como político: tal es el caso de su actuación como diputado. Aun cuando desconocemos si hubo un acercamiento efectivo entre el grupo moderado y Riva Palacio, sí sabemos que mantuvo una relación estrecha con Gómez Pedraza, líder de este grupo durante varios años y con quien, por cierto, desayunaba al lado de Guillermo Prieto, Manuel Terreros, Lucas Bal- 


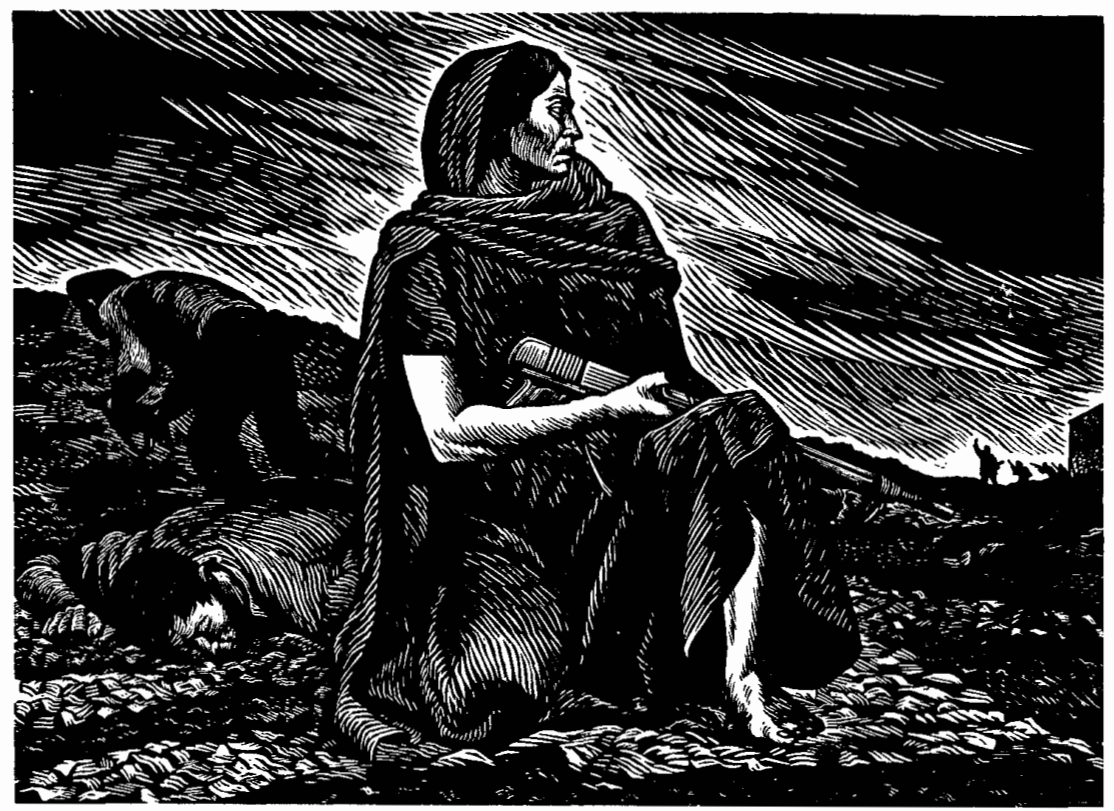

deras y Manuel Madariaga. ${ }^{29}$ La correspondencia entre ambos revela que Gómez Pedraza lo consideraba su confidente y lo consultaba sobre poblemas personales y de política. Esta relación se intensificó seguramente debido a que las actividades políticas de ambos coincidieron en no pocas ocasiones, por ejemplo, como diputados al Congreso de 1842 cuando votaron contra el proyecto de la mayoría, es decir, apoyando a la minoría que "asentaba

${ }^{29}$ Prieto, Memorias, 1906, t. II, pp. 123-126. Para abundar sobre los moderados y en particular sobre Manuel Gómez Pedraza, véase Solares, Revolución, 1996. que, el sistema bajo el cual ejercía sus derechos la nación era, además de representativo, republicano y popular: federal". Razón suficiente para que Antonio López de Santa Anna, a la sazón presidente de la república, advirtiera a los miembros de su gobierno que se opondría a toda Constitución que pretendiera regresar al federalismo. En consecuencia, esta votación culminaría con la clausura del Congreso y la posposición, para un poco más adelante, de la vuelta al sistema federal. ${ }^{30}$

${ }^{30}$ Solares, Revolución, p. 169. Sobre el Congreso, véase la obra de Noriega, Constituyente, 1986. 
Los destinos de estos hombres se cruzarían de nuevo hacia 1843 , ya que Mariano Riva Palacio fue hecho prisionero junto con Manuel Gómez Pedraza, José Ma. Lafragua, Mariano Otero y José Ma. Olaguíbel, pues se les acusaba de participar en una revolución promovida por el caudillo suriano Juan Álvarez. El procedimiento penal seguido contra estos personajes fue considerado por demás irregular y, de hecho, no pudieron probárseles los cargos, por lo cual, luego de permanecer incomunicados más de un mes, fueron liberados después de que se negaron a aceptar la amnistía ofrecida por Santa Anna. ${ }^{31}$ Sin embargo, ésta no sería la primera ni la última aventura que viviría al lado de Pedraza, pues cuando los diputados se trasladaron a Querétaro a raíz de la ocupación de las fuerzas estadunidenses de la capital, Riva Palacio y Gómez Pedraza viajaron juntos en caravana protegiéndose de los continuos asaltos de los bandidos y de las mismas tropas yanquis. Años más tarde, a la muerte de su amigo mutuo Mariano Otero acaecida en 1850, fungiría como albacea de sus bienes al lado de Pedraza. De hecho, sólo la muerte de este último ocurrida en julio de 1851 , separaría a estos hombres que contribuyeron a marcar el derrotero de la nueva nación con sus actividades, en diversos campos de la política y de la administración pública.

31 "Sumaria formada al general Manuel Gómez Pedraza, licenciado José Ma. Lafragua, Mariano Riva Palacio y licenciado Mariano Otero, por el delito de conspiración", año de 1843, en Archivo Histórico de la Secretaría de la Defensa Nacional, ramo Histórico, año de 1844, exp. $\mathrm{xI} / 481.3$, f. 1985.
Poco se sabe de las actividades de Riva Palacio entre 1843 y 1849. Para estas fechas, desempeñaba la cartera de Justicia (del 7 de diciembre de 1844 al 11 de agosto de 1845), con lo cual, podemos conjeturar que conoció muy de cerca los datos que reflejaban las estadísticas solicitadas desde 1842 (encontradas en el AGN y que se mostrarán más adelante) y bien pudo haberle llamado la atención el hecho de que, el Estado de México que gobernaría posteriormente, mostrara cifras tan alarmantes en cuanto a bandidaje. Por entonces, también se haría cargo del Ministerio de Hacienda en dos periodos coincidentes con el de Justicia (del 9 al 24 de diciembre de 1844 y del 19 de enero al 27 de marzo de 1845), lo cual formó posiblemente en él una idea muy precisa de lo que sucedía a nivel nacional con la delincuencia. A través del rastreo de estas relaciones personales, podemos afirmar que en el mes de agosto de 1843, resultó elegido compromisario de acuerdo con las elecciones primarias prevenidas en las Bases Orgánicas de la República. Posteriormente, hacia el mes de abril de 1846 , cuando ya Riva Palacio estaba alejado de sus tareas ministeriales, el general Mariano Paredes y Arrillaga, preocupado por su situación en el gobierno, buscó el apoyo del grupo moderado convocando a una reunión a Manuel Gómez Pedraza, Mariano Otero, Mariano Riva Palacio y Pedro García Conde; sin embargo, al plantearles algunas de sus propuestas, éstos no lo apoyaron. ${ }^{32}$

\footnotetext{
32 Véase Solares, Revolución, 1996, pp. 189 y 210 . También véase Santoni, "Federalistas", 1987 , pp. 238-239.
} 
Resulta muy probable que además de la política, estuviera atendiendo sus haciendas, pues era común en los políticos de la época que alternaran sus negocios personales con sus tareas en el gobierno. De hecho, no estuvo tan alejado de la sociedad y la política, ya que resultó propuesto para gobernador del Estado de México ese año de 1849. Las razones para esta nominación, según el punto de vista de Clyde Gilbert Bushnell, se orientan hacia las ligas afectivas que lo unían con Juan Álvarez y a los intereses de éste en particular encaminados a la creación de un nuevo estado, el de Guerrero. Justo es señalar que si bien desde 1835 , Juan Álvarez intentaba erigir dicho estado, muchos obstáculos en contra habían pospuesto este anhelo. Uno de ellos lo constituyó el gobernador mexiquense Mariano Arizcorreta, quien tenía intereses personales en las minas de Sultepec y no deseaba que este partido, uno de los más importantes del estado, se separara de México. Pero los pueblos que componían el partido de Sultepec eran partidarios de Álvarez y no estaban dispuestos a esperar a que la cuestión se ventilara en el Congreso. Por ello, Bushnell asevera que

la experiencia de Álvarez con los gobernadores Arizcorreta y Olaguibel lo convenció de que su única esperanza en su proyecto para el bien de su amada tierra sureña era lograr que un amigo del sur se convirtiera en el primer magistrado del estado. Por ello hizo acopio de toda su fuerza e influencia para colocar a su amigo Riva Palacio en tan importante posición. ${ }^{33}$

${ }^{33}$ Bushnell, Carrera, 1988, pp. 184-187. Las cursivas son mías. Es muy probable que influ-
La correspondencia salvaguardada en Austin confirma esta situación en diferentes momentos de las gestiones de Álvarez por lograr la creación de Guerrero. En una misiva de éste, desde su hacienda denominada La Providencia, señala las dificultades que tuvo para lograr la cooperación de Arizcorreta y la oposición abierta de diversos sectores a su proyecto. ${ }^{34}$

Mas según esta correspondencia y a pesar de la amistad que lo unía a Juan Álvarez, Mariano Riva Palacio no estaba muy convencido en cuanto a aceptar la gubernatura del Estado de México; ello se desprende de la comunicación del 24 de agosto de 1849 en donde Luis Rovalo le rogaba aceptara el cargo. Finamente, el 31 de agosto la Secretaría del Congreso del Estado Libre y Soberano de México anunció por decisión unánime la elección de Riva Palacio como gobernador. ${ }^{35} \mathrm{Al}$ parecer, la presión ejercida por Álvarez había dado frutos encaminados a lograr su objetivo.

$Y$ es que en efecto, Riva Palacio reunía muchas cualidades para el puesto a desempeñar: conocía sobre legis-

yera el hecho de que Riva Palacio estuviera casado con la hija de Guerrero para que apoyara la idea de Álvarez en cuanto a la erección del estado que llevaría el nombre de su suegro. Resulta significativo que fuera encargado de dar la oración fúnebre, en la ceremonia del traslado de los restos de Vicente Guerrero al cementerio de Santa Paula en 1842.

${ }^{34}$ Juan Álvarez [a Mariano Riva Palacio], 12 de julio de 1848, BLAC, 2794.

35 [Decreto del 31 de agosto de 1849 nombrando gobernador constitucional del Estado al C. Mariano Riva Palacio para el bienio corriente contado de marzo de 1849 a igual fecha de 1851] en Colección, 1851, t. IV, p. 31. También véanse las misivas en BLAC, 3099 y $3107 \mathrm{~A}$ respectivamente. 
lación, pues había sido diputado y senador; como ministro de Hacienda, sabía del estado financiero de la república y, en particular, del de la entidad mexiquense; contaba con muchas relaciones en el campo personal y político por los cargos desempeñados y, por si esto fuera poco, sabía que una plaga asolaba al país y, por ende al estado: el bandidaje.

\section{EL GOBERNADOR}

Gobernar al Estado de México resultaba bastante complicado por varias razones a que ya hemos hecho referencia: sus vías de comunicación, sus dimensiones, su particular geografía. A todo ello se agregaban otros factores relacionados directamente con el bandidaje, pues al parecer, las partidas de ladrones que llegaban al estado huyendo de otros eran numerosas, por colindar el Estado de México con, por lo menos, siete estados más, de ahí la condición favorable para que delincuentes de otros estados invadieran el mexiquense. Así lo comunicaba José del Villar a Riva Palacio en una carta escrita en San Ángel, el 1 de octubre de 1849 , en donde le comentaba que "por estos montes y pueblos no ha quedado ningún bandido. He hecho que los recorran todos. Ya se metieron a México, en donde por sólo este rumbo entraron como 200 [...]." ${ }^{36}$

Las acciones emprendidas por su parte para atacar este problema no se hicieron esperar y, como lo hemos se-

${ }^{36}$ [Carta de José del Villar a Mariano Riva Palacio], 1 de octubre de 1849, en BLAC, 3217. ñalado, apenas tomó posesión de la gubernatura dictó varias disposiciones, algunas de ellas encaminadas a atacar de manera directa el problema del bandidaje y la inseguridad, como el decreto del 11 de octubre de 1849. Al parecer, éste estaba dando buenos resultados, según lo reportaba uno de los comandantes encargados de la seguridad en la entidad:

Señor licenciado don Mariano Riva Palacio. Temascaltepec, octubre 13, 1849. Mi apreciable amigo y señor:

Dos son mis primeras ocupaciones en el distrito: conservar el orden como lo he conseguido hasta aquí y perseguir a los malhechores que tanto abundan en el estado, debido a nuestras continuas revueltas; pero una vez consolidada la paz, entiendo que lograremos exterminar esta mala semilla, y tengo la mejor disposición para salir a perseguir personalmente hasta conseguir su exterminio; pero se me presenta la grave dificultad de no contar con un real seguro para sueldos, pues lo muy poco que puedo facilitar a la tropa me lo proporciona mi amigo, el administrador de tabacos, a quien le debo del mes pasado al presente cerca de 500 pesos que no he podido cubrirle[...] [esta situación permite a los bandidos] que sus robos los hagan cuando por necesidad falta la custodia en los referidos caminos [...] Estevan V. León. ${ }^{37}$

${ }^{37}$ [Carta de Estevan V. León a Mariano Riva Palacio], 13 de octubre de 1849, en BLAC, 3273. La norma se aplicaba y al parecer seguía dando buenos resultados, según la misiva de $F$. Campero a Riva Palacio escrita en febrero de $\mathbf{1 8 5 1}$ en donde le exponía que, desde "[...]hace tres o cuatro meses que estando en una hacienda nuestra en los Llanos de Apan se me fue a pedir auxilio contra cuatro ladrones que acababan de 


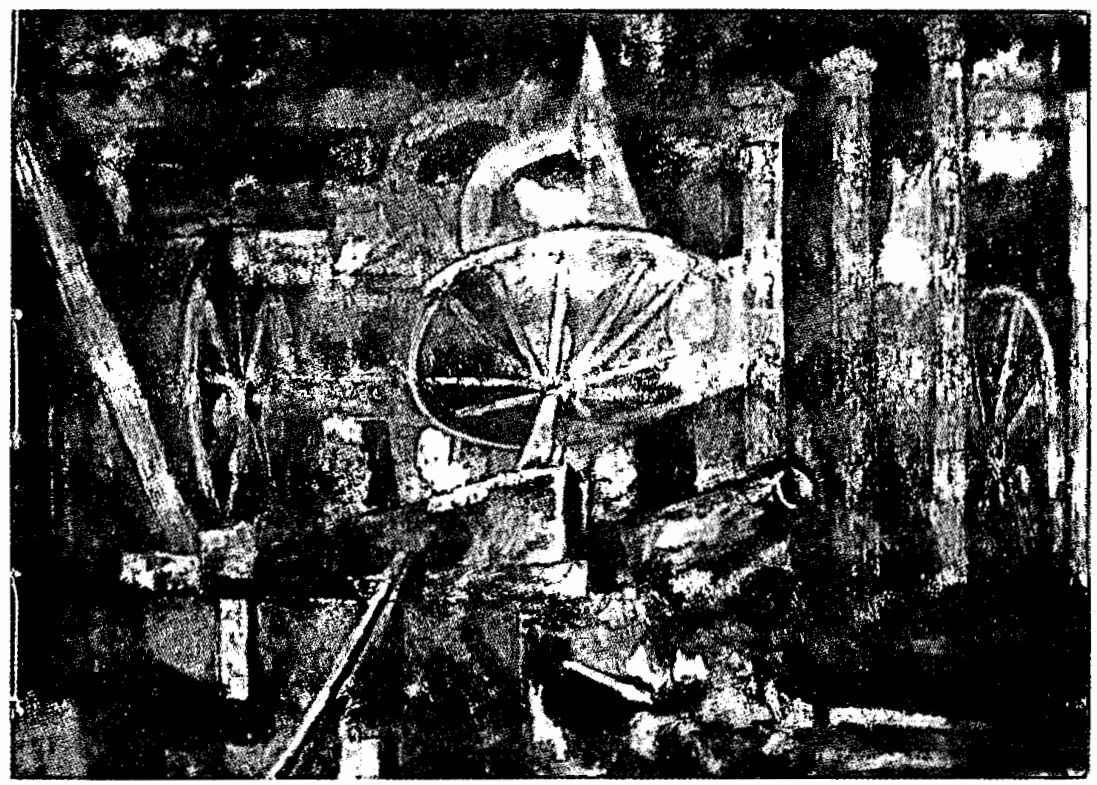

La situación planteada por el comandante militar León no era privativa del Estado de México, de donde Riva Palacio era gobernador desde el 31 de agosto de 1849, ya que el bandidaje afectaba a la mayoría de los estados que integraban la república méxicana.

robar en aquellas inmediaciones; salí en el acto con algunos sirvientes y logré alcanzar y aprender a dichos ladrones que puse a disposición de este juez. El señor Revollar con el celo y la energía que lo distinguen de la mayor parte de los jueces del estado, sustanció la causa y les aplicó la última ley de ladrones que dio la Legislatura, condenando a la última pena a dos de ellos, Timoteo Baños y Lino Buendía [...]". [F. Campero a Mariano Riva Palacio], s.d., febrero de 1851 , en BLAC, 5072 .
Un buen número de ellos no contaba con recursos para enfrentarlo. Por ello, el mandatario creyó oportuno dictar una nueva ley de contribución personal estatal, con la cual se obtendrían recursos para atacar éste y otros problemas. Aun cuando se tenía la desafortunada experiencia del decreto similar del 2 de junio de 1849, que imponía un tributo a todos los varones de 18 a 60 años, y que no había dado los frutos esperados por la dificultad para crear los padrones para el cobro y por la miseria y poca voluntad de la mayoría de la población, el 9 de febrero de 1850 , se dispuso mediante una nueva norma que la contribución se extendía a todos los varones entre 16 y 
60 años de edad, quienes deberían pagar un real mensual. Se pensaba que, al aumentar los contribuyentes, por extender la edad a los 16 años, la medida tendría éxito. Sin embargo, no fue así debido a que varios factores se combinaron: uno de ellos lo constituyó la multitud de errores en la conformación de los padrones al incluir exceptuados menores de 16 años incapacitados físicamente; otro, la falta de voluntad de los ciudadanos para conformar los padrones; uno más era la falta de capacidad económica de la mayoría de la población para reunir el real para el pago mensual, debido a sus bajos ingresos y, por último, el cólera morbo que para agosto de ese año, hizo su aparición en la entidad. ${ }^{38}$ De esta forma, el gobernador tuvo que aceptar que, por este medio, no se podrían reunir fondos para mejorar la situación económica del estado y enfrentar así al bandidaje.

Aun cuando para esta época la actividad minera había salido de su etapa de esplendor, seguía redituando algunas ganancias a nivel estatal, mediante el cobro de impuestos a quienes explotaban los minerales. Por consecuencia,

\footnotetext{
${ }^{38}$ González, Anatomía, 1977, pp. 182-183. Los decretos sobre cobro de contribución personal se habían dado a nivel federal desde el 21 de agosto de 1840 con el nombre de "impuesto de capitación", posteriormente el 26 de abril de 1841 se dictó otra norma de "contribución per. sonal" y el 7 de abril de 1842 otro denominado "derecho de capitación". Este último determinaba el cobro a todos los varones de 16 a 60 años de edad, los cuales deberían pagar un real mensual. Seguramente en éste se apoyó Riva Palacio para el decreto que aprobó a nivel estatal. Véase Solares, "Bandidaje", 1997.
}

los traslados de la mercancía extraída del centro de la tierra seguía llamando la atención de los salteadores de caminos, sobre todo cuando empresarios como Francisco Murphy, el principal accionista del mineral de El Oro, solicitaba la ayuda y protección de las fuerzas gubernamentales para trasladar sus conductas repletas de oro y plata hacia la ciudad de México para llevarlas a algún otro destino, como el puerto de Veracruz. Esta situación de bonanza minera, que en diversos puntos y momentos invadió al territorio mexiquense en lugares como Sultepec y El Oro, dio pie a que algunos inversionistas ingleses y alemanes se trasladaran a México resueltos a invertir, envueltos en los relatos y promesas de que harían fortuna. Algunos de ellos sí lo consiguieron, pero la mayoría tuvo que enfrentar no sólo la turbulenta vida minera, sino el constante embate de los salteadores y ladrones de caminos. Y es que, según Anne Staples, el bandidaje impedía el desarrollo de actividades mineras, políticas, económicas y sociales a tal punto que:

Llegar hasta El Oro desde Inglaterra era una odisea tan emocionante que los mineros lo recordaban décadas después. Sus relatos ayudan a entender el grado de inseguridad que reinaba en la república durante la primera mitad del siglo. "Brother" Absalom Noble, uno de los mineros de Cornualles que estuvo entre el primer grupo a arribar, recordaba que lo asaltaron cuatro veces entre Veracruz y El Oro. Había tomado una diligencia entre Veracruz y la ciudad de México, luego un caballo hasta la mina. No importaba el medio de transporte. Cualquier viajero, incluyendo este mi- 
nero extranjero, fortachón[...]no asustaba a los bandidos $[\ldots]^{39}$

Esta aseveración de Staples resulta acertada, si nos atenemos al cúmulo de noticias aparecidas en los periódicos durante esta primera mitad del siglo XIX y a la evidente incapacidad del estado y de sus gobernantes para brindar recursos económicos adecuados a los sectores desprotegidos de la sociedad, así como una justicia pronta y eficiente.

Si bien la mayoría de los caminos de la república mexicana eran asolados por la plaga del bandolerismo, en la entidad mexiquense esta situación se vería magnificada debido a lo especial de su situación geográfica. Es decir, mientras otros estados se preocupaban por contener a los malhechores de una o dos entidades limítrofes, en el caso de México había que preocuparse por contener o defenderse de, por lo menos, siete vecinos. En este sentido, sus cárceles se hallaban repletas y, por lo tanto, resultaba muy dificil conseguir la manutención de innumerables delincuentes. Esto agravaba la situación económica del estado; de ahí que Mariano Riva Palacio siguiendo las medidas adoptadas en muchos de los casos por la federación, como ya to constatamos en el caso del impuesto de contribución personal, dictó una ley el 12 de octubre de 1850, que autoriza-

\footnotetext{
${ }^{39}$ Staples, Bonanzas, 1994, p. 130 . No sólo los mineros que venían dispuestos a hacer fortuna en territorio mexicano se vieron asediados por los bandidos, muchos viajeros en busca de placer y diversión se toparon con estos personajes en diversos caminos de la república. Para más detalle, véase el capítulo I de la obra de Solares, "Bandidaje", 1997.
}

ba a destinar a los reos sentenciados a presidio a trabajar en las minas y en la apertura de caminos, entre otros trabajos. La idea adoptada por Riva Palacio y por el gobierno federal, tenía su origen en un concepto venido de Europa y Estados Unidos y difundido ampliamente en México, de algunos reformadores que sugerían utilizar el cuerpo del delincuente en lugar de acabar con él; por ello proponían recurrir con mayor frecuencia a penas consistentes en la realización de trabajos públicos, así

el culpable paga dos veces: por el trabajo que suministra y por los signos que produce en el corazón de la sociedad, en medio de las plazas públicas o en el camino real; el condenado [era] un foco de provechos y de significados. ${ }^{40}$

De esta forma, el castigo transformado en trabajo, resultaba ejemplar y aligeraba un poco la carga consistente en la manutención de los presos.

Si bien las leyes que hemos mencionado no fueron las únicas promulgadas por el gobernador Riva Palacio en su primer periodo de gobierno, solamente hemos expuesto aquellas que se relacionan con el tema tratado. Las medidas intentaron sanear al estado asolado por el bandidaje y en algunos momentos lo lograron; sin embargo, no sería suficiente ninguna medida a nivel estatal -ni a nivel federal- en casi toda esa centuria, pues el problema a enfrentar resultó mucho más grave de lo que pudieron imaginarse los hombres que tuvieron en sus manos el poder durante esos años.

${ }^{40}$ Foucault, Vigilar, 1984, pp. 110-113. 
Hacia 1857, en su segunda y breve gestión como gobernador estatal, Riva Palacio presentó un balance ante la Legislatura el 15 de octubre de ese año, en términos por demás desalentadores:

A mi regreso al mando hube de resignarme a permanecer en él por tiempo indefinido, por todo el que lo exigieran las dolorosas e imprevistas circunstancias en que vine a encontrar al estado; invadido repentinamente por numerosas gavillas que, bajo el pretexto de levantadas en defensa de una causa religiosa y política, traían la siniestra misión de trastornar el orden público y de no dejar momento de reposo a los habitantes $y$ autoridades del estado $[. ..] .^{41}$

Al parecer, no se resignaba a que su estado estuviera asolado de nuevo por el bandidaje, aun cuando éste, en ese momento, tuviera como origen otras causas que las aquí planteadas.

\section{LAS ESTADISTICAS}

Si bien la década de los cuarenta ha sido estudiada hasta la saciedad por especialistas estudiosos de la guerra contra Estados Unidos, ha sido descuidada en otros aspectos igual de importantes, poco o nada atendidos, como el bandidaje o la administración de justicia. De ahí que resulte importante destacar que, durante esta década, se dieron los primeros pasos para detectar cuán grave era la delincuencia en México. Parece ser que por primera vez se intentaba cuantificar el problema, pues si bien se intuía que era gra-

${ }^{41}$ Renuncia, 1857, p. 4. ve, se desconocían sus dimensiones. Fue hacia 1842 que surgió en el gobierno de corte centralista la intención de elaborar estadísticas que reflejaran de manera gráfica dicho problema. Esta situación le imprime un doble atractivo a la década y al tema del bandidaje ya que, al parecer, ningún gobierno federalista se había interesado en cuantificarlo. El centralista, al intentarlo, brindaba una opción nueva para atacarlo, la de saber con números cuál era la dimensión de la delincuencia en México.

En ese año, el ministro de Justicia, Crispiniano del Castillo, solicitó a todos los departamentos que remitieran noticias para la formación de una estadística judicial; así, las circulares enviadas a los gobernadores y tribunales superiores intentaban resumir de una manera importante, datos sobre los juzgados de letras existentes, funcionarios, alcaldes y jueces de paz, además de los sueldos que percibían estos funcionarios; sobre las salas de los tribunales, los ministros y otros empleados, así como la antigüedad y los salarios correspondientes a éstos. Se pedían también informes acerca de los tribunales mercantiles y las causas comunes concluidas, con los nombres de los reos y prisiones a donde habian sido destinados; precisiones acerca de los delitos cometidos, los jueces que llevaban sus causas y las respectivas sentencias de primera, segunda y tercera instancias. Al final de cada documento debería incluirse un resumen de los presidiarios condenados por cada delito y otro de las penas a que habían sido sentenciados. Aun cuando las estadísticas llevaron demasiado 


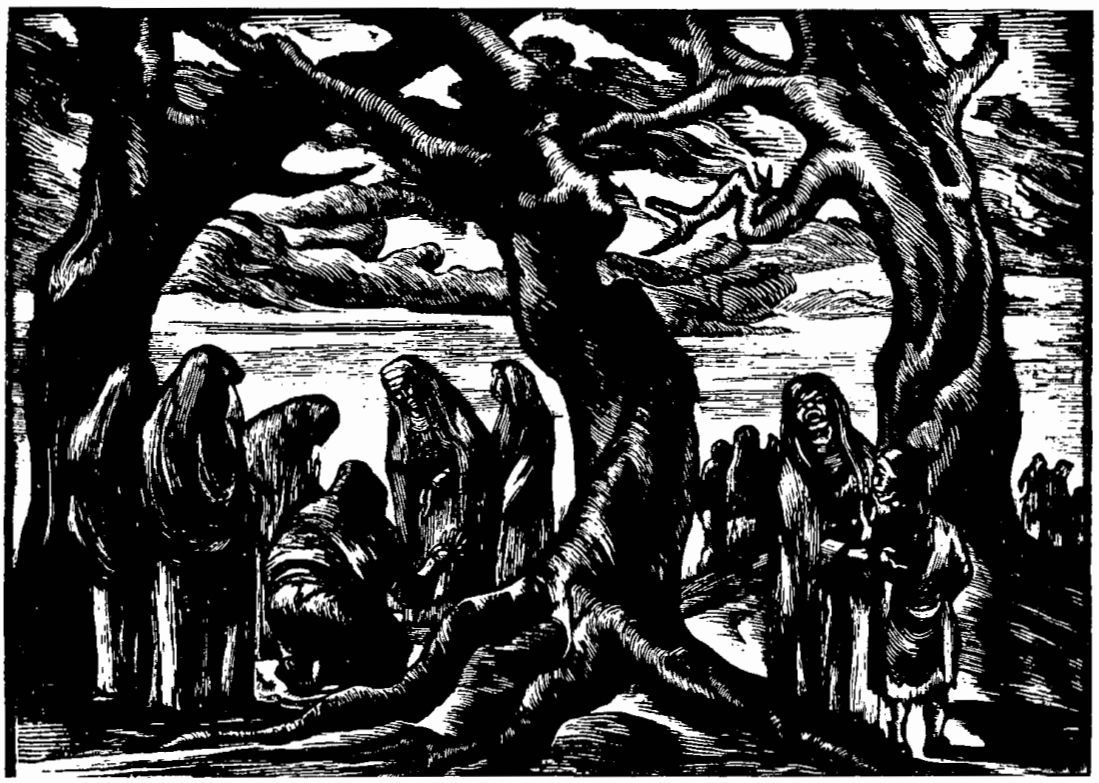

tiempo para realizarse y remitirlas al gobierno y, lamentablemente, sólo una porción de la información se encuentra resguardada en el Archivo General de la Nación, constituye un invaluable censo estadístico cuya mayor parte la conforman los informes sobre los presos en un buen número de departamentos, incluyendo el de México. Éstos dan cuenta del nombre, estado civil, oficio, edad, delito y grado de educación de cada uno de ellos, así como el resumen numérico de los delitos cometidos por los convictos y los oficios a que se dedicaban. ${ }^{42}$

${ }^{42}$ Las estadisticas se encuentran en el Archivo General de la Nación, ramo Justicia, caja
La información remitida al gobierno hasta noviembre de 1845 resulta por demás novedosa, ya que concentra el problema del bandidaje a nivel nacional acaso por primera vez $y$, por otra parte, nos indica que los departamentos más afectados por la delincuencia eran, en orden decreciente: México, Puebla, Guanajuato, Durango, Aguascalientes, Sinaloa, Veracruz, Michoacán y el distrito de Acapulco (que más tarde se convertiría en Guerrero). Esto

300 , exps. 18, fs. $256,258,262,266,268,270$, $271,273-276,281,283,288,292,296-300,302$, $305-306,309-310,313,315,319-322,327-340$, 342 , 345-253, 355, 358-359, 362, 365-367, $377-$ 379. Para más detalles sobre el problema del bandidaje, véase Solares, "Bandidaje", 1997. 
resulta lógico si reflexionamos en que el Estado de México era (por entonces $y$ al igual que las otras entidades convertidas en departamentos por el sistema central), un territorio de enormes dimensiones que agrupaba numerosos distritos con una prominente actividad agrícola y era además vía obligada hacia muchos lugares; por otra parte, era el punto más cercano a la capital del país: Puebla era, por su parte, considerado clave como paso obligado hacia Veracruz, el puerto más importante de la república, y como núcleo también imporante de artesanos. Guanajuato se consideraba el estado más relevante del Bajío por estar enclavado en la zona minera más sobresaliente y, por lo tanto, rica en actividades relacionadas con este ramo. Durango, destacaba en cuanto a cría de ganado destinado al consumo en otras regiones del país. En el caso de Michoacán, Veracruz, Acapulco y Sinaloa, las estadísticas no están completas, ya que se refieren sólo a algunos de los partidos o municipios que componían los departamentos, pero aun así, resulta evidente que reflejan que el problema del bandidaje también era bastante grave para entonces en esos lugares.

En la mayoría de las entidades, el delito más frecuentemente señalado resultó ser el robo y el oficio que más se mencionó fue el de gañán, seguido muy de cerca por el de jornalero y labrador, todos ellos significativamente relacionados con el trabajo de la tierra. Las cifras a propósito del analfabetismo resultaron abrumadoras, ya que la mayoría de los infractores no sabía leer ni escribir. Significativamente, estos datos se repiten en la mayoría de las estadís- ticas correspondientes a otros departamentos, por lo cual, debemos suponer que era un denominador común que la mayoría de los hombres involucrados en hechos delictivos carecían de la más elemental educación. (Véase gráfica 1).

Las estadísticas muestran también que la mayoría de los bandidos estaban casados, lo que nos lleva a pensar que sus necesidades eran mucho mayores que las de un hombre célibe, pues debían sostener económicamente a una familia, de ahí que estuvieran más precisados de delinquir considerando que el trabajo escaseaba y que no contaban con ningún oficio que les permitiera conseguir una mejor remuneración (véase gráfica 2). El grupo de edades en donde se aprecia un mayor porcentaje de delitos oscila entre los 20 y los 30 años, es decir, hombres jóvenes en plena etapa productiva y que, debido al promedio de vida que se alcanzaba por entonces, se acercaban a su etapa de madurez y de muerte (véase gráfica 3). Conjugando estos datos, podemos apreciar así el perfil del bandido: jóvenes, casados y analfabetos, dedicados en su gran mayoría al trabajo de una tierra de la cual no eran dueños. Por si esto fuera poco, algunos sólo trabajaban en temporada de siembra o cosecha, según las necesidades de las haciendas.

Claude Morin, que ha trabajado principalmente el caso de Michoacán, señala que un trabajador permanente que laborara 270 días al año, recibía por jornal cuatro pesos mensuales y una ración semanal de maíz; en promedio, laborando nueve meses del año, obtenía 36 pesos anuales de los que se dẹs- 


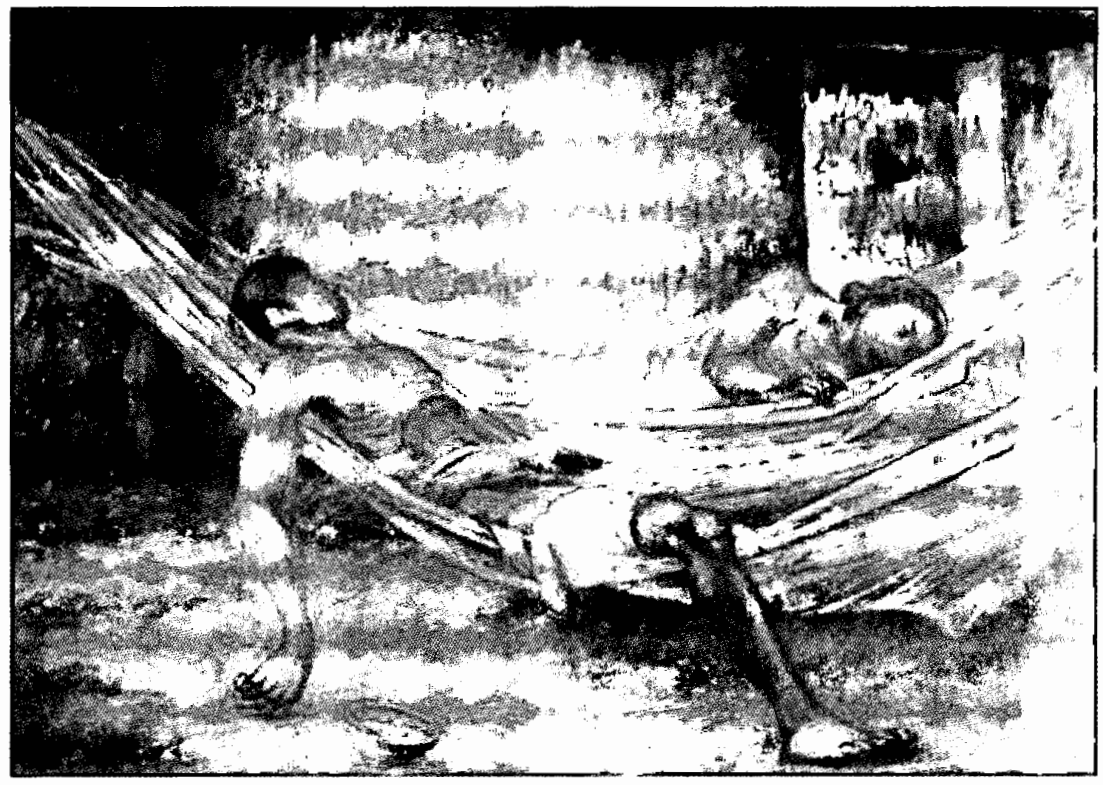

contaban los días no laborados -por razones imputables o no a él-, así como los productos que consumía o recibía a cuenta de su salario. ${ }^{43} \mathrm{Si}$ bien cada una de las entidades de la república contaba con particularidades que la hacían diferente en cuanto al tipo de producción, haciendas y cultivos, estas cifras dadas por Morin nos sirven de referencia sobre cuál era el salario que podía percibir un empleado relacionado con el trabajo de la tierra. Para tener una idea de las diferencias salariales, según el trabajo desempeñado en la hacienda, el mismo autor nos señala que el capataz, el hortelano, los boye-

${ }^{43}$ Morin, Michoacán, 1979, pp. 215-266. ros y los vaqueros ganaban, aproximadamente, 48 pesos anuales y recibían tres almudes de maíz cada semana; el administrador recibía como salario 500 pesos al año y el mayordomo, 150 pesos más una pensión de cuatro reales a la semana, medio carnero y una fanega de maíz. Los desniveles resultan más que evidentes y explican, en alguna medida, las razones que tenían para delinquir.

En el caso concreto del departamento de México, las estadísticas nos muestran que hacia 1845 , fecha en que gobernaba el presidente José Joaquín de Herrera, las actividades comerciales estaban muy diversificadas a diferencia de otros departamentos, lo cual propi- 
ciaba una correspondencia menos perceptible entre los delitos y los oficios de los delincuentes que asolaban a la entidad. Si analizamos la gráfica 4, podremos apreciar que el oficio en que más se delinquía era el de jornalero, seguido por los de labrador, operario, arriero, zapatero y tlachiquero. Las cifras se vuelven menos significativas en los casos de los otros oficios.

Por último, las estadísticas nos permiten conocer que, de un número aproximado de 2712 delincuentes presos en diferentes puntos del país en 1845, 797 de ellos correspondían al departamento de México, 743 al de Puebla, 622 al de Guanajuato, 191 al de Durango y 117 al de Aguascalientes. Completan las cifras: 68 de Sinaloa, 67 de Veracruz, 66 de Michoacán y 33 de Acapulco (Guerrero), entidades que, como ya hemos aclarado, ofrecen sólo datos parciales tal vez porque los demás se extraviaron o no se integraron a tiempo. Sin embargo, los números nos vuelven a plantear que el caso del departamento de México era superior en cuanto a delincuencia a los demás que integran las estadísticas.

Así las cosas, se antoja como lógico que Mariano Riva Palacio fuera designado gobernador del Estado de México, ya que su paso por los distintos ministerios lo había preparado para atacar el grave problema que ya hemos señalado. Esto pareció confirmarlo con sus acciones cuando siendo gobernador por primera vez, organizó la receptoría de rentas, fundó una caja de ahorros, una de beneficencia, dio un combate frontal al bandolerismo y construyó un mercado y una cárcel pública, entre otras cosas; y es que para enton- ces, el gobernador Riva Palacio contaba con recursos nuevos gracias a un proyecto iniciado en 1847 que estaba dando frutos.

Para tratar de entender el alcance de éste tiene que considerarse el hecho de que, antes de que se iniciara,

[...] los gastos ordinarios de tipo administrativo (básicamente sueldos de los empleados del poder ejecutivo, judicial y legislativo) eran los principales rubros de la Tesorería estatal[...]en cambio, surgen como un elemento decepcionante los niveles abismalmente bajos de inversiones estatales en obras públicas, en instrucción pública y en el ámbito de la salud y lo social $[\ldots]^{44}$

Así las cosas, resulta de particular importancia el periodo que va de 1847 a 1852 en la entidad mexiquense, porque fue entonces cuando se llevó a cabo "lo que posiblemente fue el más exitoso de los proyectos de modernización fiscal de la república mexicana antes del Porfiriato". El creador del decreto que tenía como punto medular la abolición de las alcabalas, fue José Ma. Olaguíbel, gobernador en turno hacia noviembre de 1847 , quien remplazó dichos impuestos por contribuciones directas sobre fincas rústicas y urbanas, producción de azúcar y aguardiente y sobre negocios y profesiones, lo que permitió que tanto Mariano Arizcorreta como posteriormente Mariano Riva Palacio, gobernadores que continuarían al frente del estado, siguieran esta política y cosecharan frutos en cuanto a

${ }^{44}$ Marichal, Historia, 1994, p. 104. Si reflexionamos en esta aseveración, encontraremos la clave para explicar la delincuencia. 
Gráfica 1. Distribución de delitos y grado de educación en el departamento de México 1845

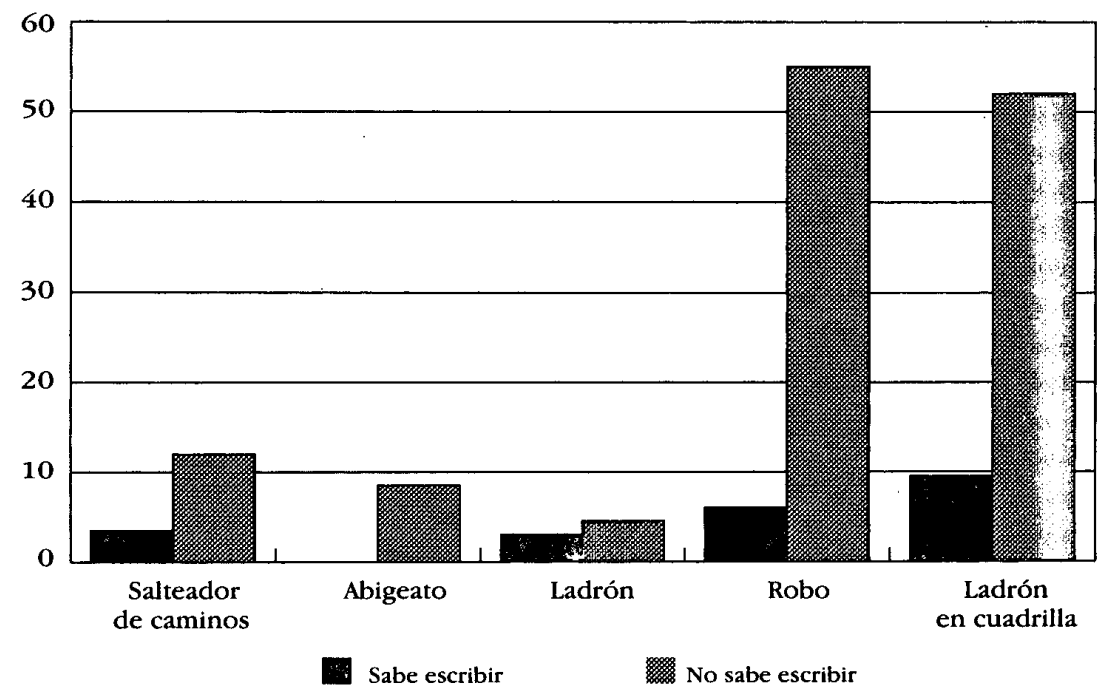

Gráfica 2. Distribución de delitos y estado civil de los delincuentes en el departamento de México 1845

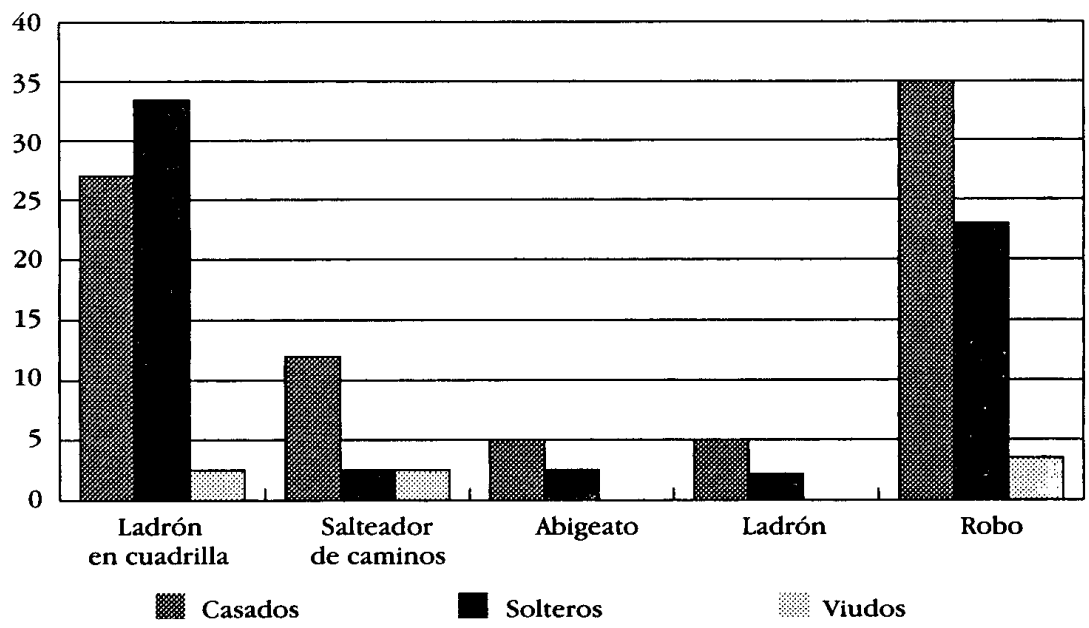


Gráfica 3. Distribución de delitos por edades en el departamento de México 1845

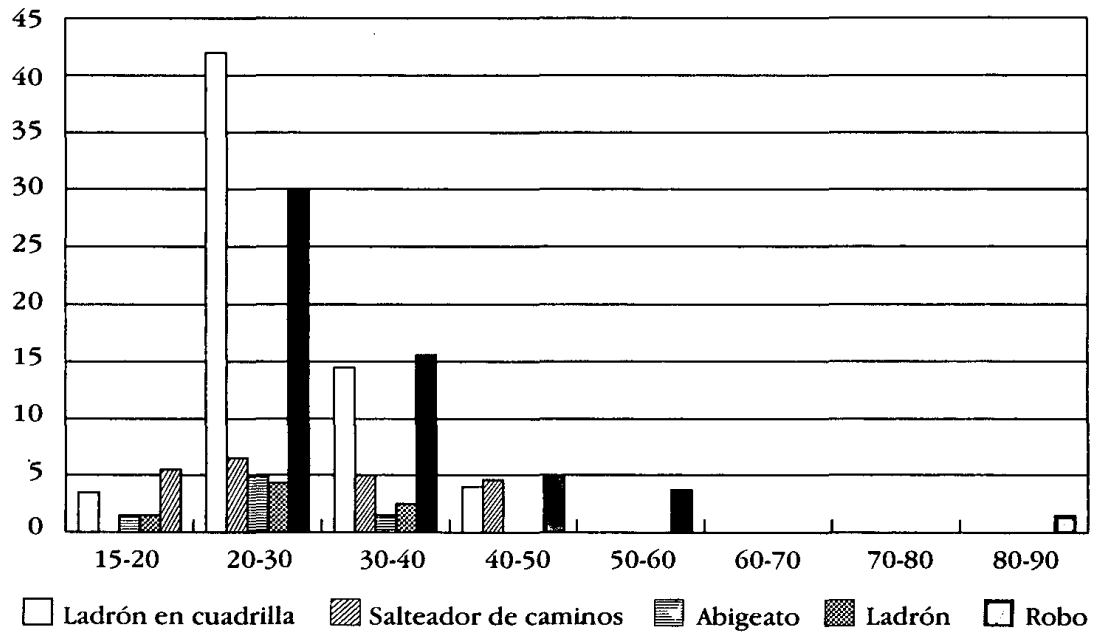

Gráfica 4. Distribución de los oficios de delincuentes presos por robo, ladrones en cuadrilla, salteadores de caminos, abigeos y asaltantes en el departamento de México 1845

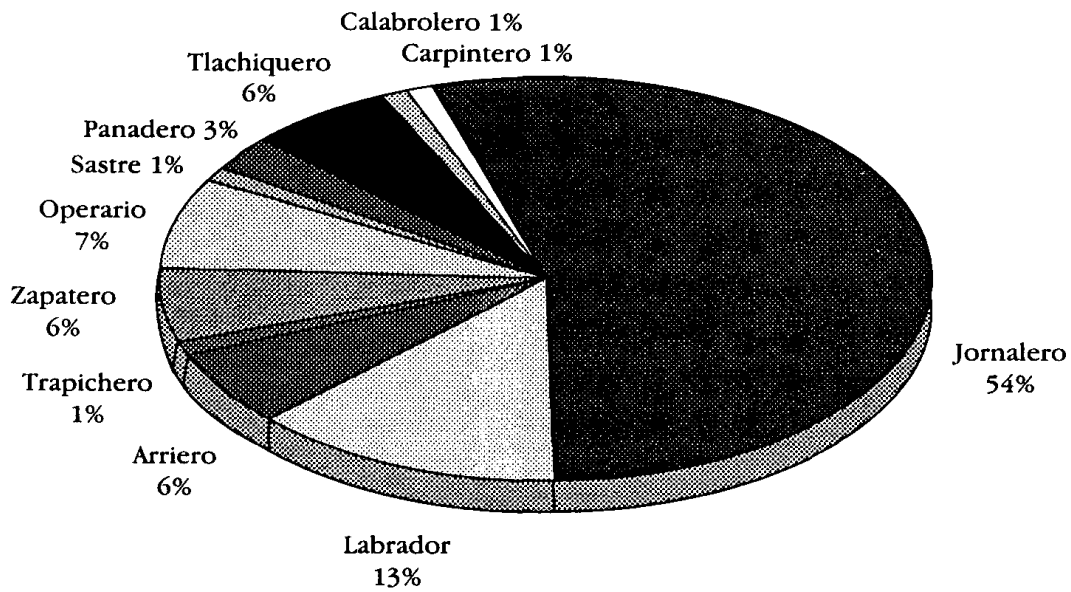


recaudación de tributos, a tal punto, que se plantearon posibilidades nunca antes contempladas, como el pago de adeudos cuantiosos y la creación de un cuerpo de rurales que influyeron decisivamente en el rumbo de la delincuencia estatal en la década de los cincuenta. También se realizó la reapertura del Instituto Literario. Esta modernización fiscal exitosa permitió atender otros rubros no considerados anteriormente como prioritarios. Desafortunadamente, todavía no se darían las condiciones que le proporcionaran al gobierno la estabilidad económica y política suficiente para atender la educación y el empleo, situación que en conjunto favorecía el bandidaje; tampoco se había podido crear un código legislativo único que permitiera aplicar la justicia con equidad, con lo cual, la delincuencia seguiría dando dolores de cabeza a los gobernantes durante varias décadas más.

Algunas razones que explicarían esta situación ya las hemos apuntado: la de ser una entidad muy extensa y poblada que concentraba enormes recursos materiales y humanos, que comunicaba a través de su territorio a la mayoría de las rutas del país y que tenía inserto al principal centro político, económico, social y religioso: la ciudad de México. Otras más quedan parcialmente resueltas en el presente trabajo debido, fundamentalmente, a que el periodo estudiado resulta muy pequeño comparado con la historia general estatal. Sin embargo, al plantearnos algunas preguntas, como la de si el Estado de México respondió al mismo patrón de delincuencia que otras entidades, podemos responder que sí, pues al pare- cer, en él se dieron las mismas causas que originaron el bandidaje en otros lugares: miseria, falta de educación, desempleo, corrupción y mala administración de justicia.

Cuando nos preguntamos si se legisló en dicho estado en forma particular sobre ladrones en gavilla y sobre asaltos en despoblado, la respuesta también es afirmativa como ya lo pudimos constatar durante el primer gobierno de Riva Palacio; y si bien no hemos encontrado referencias particulares a la aplicación en esta época de preceptos coloniales, tal vez porque ya estaba muy alejado el siglo XVIII para entonces, sí pudimos advertir que en muchas ocasiones, el gobierno estatal se rigió por las disposiciones legales dictadas a nivel federal, expidiendo algunas que resultaron muy semejantes.

Por ello, resulta inevitable conside. rar que ni el gobierno federal ni el centralista lograron consolidar un estado equilibrado, capaz de atender de igual manera los asuntos políticos, económicos y sociales para permitir el desarrollo pleno del país y de sus habitantes. Muchos gobernantes federales y estatales lo intentaron, tal fue el caso de Mariano Riva Palacio; sin embargo, no pudieron aliarse para conjuntar esfuerzos y dar estabilidad a la nación, requisito indispensable para lograr el progreso y la tan anhelada modernidad. De ahí que el bandidaje haya surgido como una fuerza avasalladora, como un reclamo, como un grito de los desposeídos y como una evidencia de la incapacidad del estado mexicano para lograr su pleno funcionamiento.

Quede esta primera aproximación al tema, como una invitación para in- 
vestigar más sobre la vida de este importante político y sobre el bandidaje en la entidad mexiquense: sobre la producción de sus haciendas, sobre los salarios que percibían los trabajadores del campo, sobre la legislación estatal en función de los salteadores de caminos, entre muchos otros temas pendientes. Por fortuna, cada día más investigadores deciden aventurarse en épocas y asuntos poco conocidos y estudiados. Baste como muestra este trabajo mío, "El bandidaje en el camino real de Michoacán. Su impacto en la vida del México del siglo XIX, 1821-1855", presentado como tesis doctoral y actualmente en prensa con el título de Bandidos somos y en el camino andamos. Bandidaje, caminos y administración de justicia en el siglo XIX (18211855). El caso de Michoacán, así como el ya conocido de Paul Vanderwood, Desorden y progreso. Bandidos, policías y desarrollo mexicano, que complementa el periodo estudiado por mí, para así tener una visión más completa del siglo XIX en cuanto' a este tema, aunque sea desde diferentes perspectivas, ya que las condiciones, políticas, económicas y sociales se habían modificado visiblemente en la segunda mitad de la centuria decimonónica. Mientras tanto, que sirva este bosquejo como punto de partida de las posteriores investigaciones que vengan a enriquecer el conocimiento histórico actual de la entidad mexiquense y del país.

\section{ARCHIVOS}

AGN Archivo General de la Nación.

AHSDN Archivo Histórico de la Secretaría de la Defensa Nacional.
AMrP Archivo de Mariano Riva Palacio, Colección Latinoamericana Nettie Lee Benson, de la Universidad de Texas en Austin. Microfilm.

\section{Hemerografía}

-El Eco del Comercio, 1847.

-El Monitor Republicano, 1847.

-El Republicano, 1846, 1847.

-El Siglo Diez y Nueve, 1845-1848.

\section{Bibliografía}

-Alamán, Lucas, Memoria de la Secretaría de Estado y del Despacho de Relaciones Interiores y Exteriores leída por el Secretario del ramo en la Cámara de Diputados el día 12 de febrero de 1830 y en la de Senadores el día 13 del mismo, Imprenta del Águila dirigida por José Ximeno, México, 1830.

-Bushnell Clyde, Gilbert, La carrera política y militar de Juan Álvarez, Gobierno del Estado de Guerrero/Miguel A. Porrúa, México, 1988.

-Colección de decretos del congreso extraordinario del estado libre y soberano de México que funcionó en la segunda época de la federación, Toluca, 1850, t. III.

- Colección de decretos del primer congreso constitucional del estado libre y soberano de México que funcionó en la se. gunda época de la federación en el biento corrido de 2 de marzo de 1849 a igual fecha de 1851, Toluca, 1851, t. IV.

-Dabbs Jack, Autrey, The Mariano Riva Palacio Archives. A guide, Ed. Jus, México, 1967.

-Foucault, Michel, Vigilar y castigar, Siglo XXI Editores, México, 1984.

-González Navarro, Moisés, Anatomía del poder en México 1848-1853, El Colegio de México, México, 1977. 
-Hobsbawm, Eric, Bandidos, Editorial Ariel, Barcelona/Caracas/México, 1976.

-Mac Lachlan, Colin, La justicia criminal del siglo XVII, en México. Un estudio sobre el Tribunal de la Acordada, SEP, México, 1976.

-Marichal, Carlos et al., Historia de la bacienda pública del Estado de México 1824-1990, El Colegio Mexiquense/Gobierno del Estado, México, 1994.

-Mora, José María Luis, "Memoria sobre cárceles inglesas" en Obras completas de José Ma. Luis Mora, investigación, recopilación y notas de Lillian Briseño, Laura Solares y Laura Suárez de la Torre, SEP/ Instituto Mora, México, 1986, t. 7.

-Moreno Coello, Georgina, "El Estado de México, la historia de un proceso de definición territorial: 1824-1917", tesis de licenciatura, Facultad de Filosofía y LetrasUNAM, México, 1993.

-Morin, Claude, Micboacán en la Nueva España del siglo XVII. Crecimiento $y$ desigualdad en una economia colonial, FCE, México, 1979.

-Noriega Elio, Cecilia, El Constituyente de 1842, UNAM, México, 1986.

-Prieto, Guillermo, Memorias de mis tiempos, 1840-1853, Librería de la vda. de C. Bouret, París, México, 1906, t. II.

-Renuncia del excmo. sr. gobernador D. Mariano Riva Palacio, y determinación que sobre ella dio la bonorable legislatura del estado, Tipografía del Instituto Literario, Toluca, 1857.

-Sánchez Colín, Guillermo, Legislación penal del Estado de México, Ed. Libros de México, México, 1975, t. I.
-Santoni, Pedro, "Los federalistas radicales y la guerra del 47 ", tesis de doctorado, El Colegio de México, México, 1987.

-Solares Robles, Laura, "El bandido social en México durante el Porfiriato", Facultad de Filosofia y Letras-uNAM, México, 1981.

, Una revolución pacífica. Biografía política de Manuel Gómez Pedra$z a, 1789$ - 1851, Instituto Mora/SRE/ Gobierno del Estado de Querétaro, México, 1996. "El bandidaje en el camino real de Michoacán. Su impacto en la vida del México del siglo XIX, 1821-1855", tesis de doctorado, Facultad de Filosofía y Letras-UNAM, México, 1997.

- Bandidos somos y en el camino andamos. Bandidaje, caminos $y$ administración de justicia en el siglo XIX (1821-1855). El caso de Michoacán, Instituto Mora/Instituto Michoacano de Cultura, México (en prensa).

-Staples, Anne, Bonanzas y borrascas mineras: El Estado de México 1821-1876, El Colegio Mexiquense, A.C., México, 1994.

-Taylor, William, B., Embriaguez, bomicidio y rebelión en las poblaciones coloniales mexicanas, FCE, México, 1987.

-Vanderwood, Paul J., Desorden y progreso. Bandidos, policías y desarrollo mexicano, Siglo XXI Editores, México, 1986.

-[Varela Luis], Memoria que el secretario del ejecutivo del estado libre de México encargado de las secciones de Gobierno y Guerra leyó al H. Congreso en los dias 26, 27 y 28 del mes de abril de 1835.

-Villari, Rosario, Rebeldes y reformadores del siglo XVI al XVII, Del Serbal, Barcelona, 1981. 


\section{SECUENCIA}

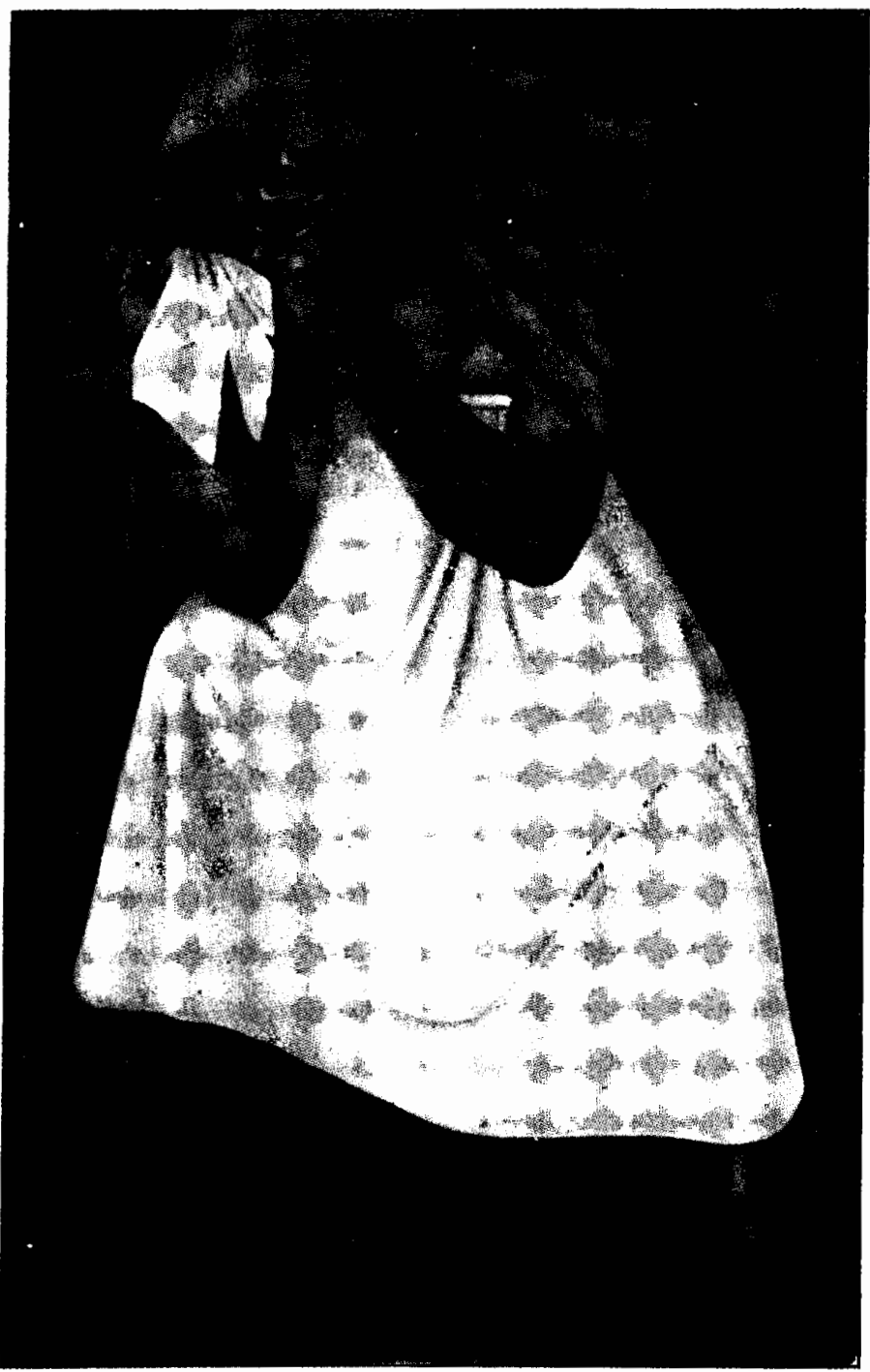

